\title{
A Theoretical Framework for the Study of Adult Cognitive Plasticity
}

\author{
Martin Lövdén \\ Lund University and Max Planck Institute for \\ Human Development
}

\author{
Ulman Lindenberger and Sabine Schaefer \\ Max Planck Institute for Human Development
}

\author{
Lars Bäckman \\ Karolinska Institutet and Max Planck Institute for \\ Human Development
}

Florian Schmiedek

Max Planck Institute for Human Development and German Institute for International Educational Research

\begin{abstract}
Does plasticity contribute to adult cognitive development, and if so, in what ways? The vague and overused concept of plasticity makes these controversial questions difficult to answer. In this article, we refine the notion of adult cognitive plasticity and sharpen its conceptual distinctiveness. According to our framework, adult cognitive plasticity is driven by a prolonged mismatch between functional organismic supplies and environmental demands and denotes the brain's capacity for anatomically implementing reactive changes in behavioral flexibility (i.e., the possible range of performance and function). We distinguish between 2 interconnected but distinct cognitive outcomes of adult cognitive plasticity: alterations in processing efficiency and alterations in representations. We demonstrate the usefulness of our framework in evaluating and interpreting (a) increments in frontal brain activations in the course of normal aging and (b) the effects of cognitive training in adulthood and old age. Finally, we outline new research questions and predictions generated by the present framework and recommend design features for future cognitive-training studies.
\end{abstract}

Keywords: adult cognitive development, aging, compensation, cognitive intervention, transfer

Aging-related reductions in cognitive performance are in full view roughly around the age of 65 . On the group level, accelerating mean decline is observed in abilities such as working memory, reasoning, episodic memory, and spatial orientation in late life (Rönnlund \& Nilsson, 2006; Rönnlund, Nyberg, Bäckman, \& Nilsson, 2005; Schaie, 1996). Different individuals display differ-

Martin Lövdén, Department of Psychology, Lund University, Lund, Sweden, and Center for Lifespan Psychology, Max Planck Institute for Human Development, Berlin, Germany; Lars Bäckman, Aging Research Center, Karolinska Institutet, Stockholm, Sweden, and Center for Lifespan Psychology, Max Planck Institute for Human Development; Ulman Lindenberger and Sabine Schaefer, Center for Lifespan Psychology, Max Planck Institute for Human Development; Florian Schmiedek, Center for Lifespan Psychology, Max Planck Institute for Human Development, and German Institute for International Educational Research, Frankfurt am Main, Germany.

Martin Lövdén is supported by the Sofja Kovalevskaja Award (administered by the Alexander von Humboldt Foundation and donated by the German Federal Ministry for Education and Research), the Max Planck Society, and Swedish Research Council Grant DNR 421-2005-2018. Lars Bäckman is supported by the Swedish Research Council, the Swedish Council for Working Life and Social Research, Swedish Brain Power, and an Alexander von Humboldt Research Award. Parts of this article were written while Ulman Lindenberger was a fellow at the Center for Advanced Study in the Behavioral Sciences at Stanford University. We thank Hannes Noack, Eduardo Mercado III, and Shu-Chen Li for stimulating and productive comments on this paper.

Correspondence concerning this article should be addressed to Martin Lövdén, Center for Lifespan Psychology, Max Planck Institute for Human Development, Lenzeallee 94, 14195 Germany. E-mail: loevden@mpibberlin.mpg.de ent levels of performance and different rates of cognitive decline in old age (DeFrias, Lövdén, Lindenberger, \& Nilsson, 2007; Lindenberger \& Ghisletta, 2009; see Figure 1). Epidemiological work suggests that in old age, a lifestyle rich in mental, physical, and social stimulation exerts beneficial influences on level of cognitive performance (Bäckman, Small, Wahlin, \& Larsson, 1999; Hertzog, Kramer, Wilson, \& Lindenberger, 2009; Hultsch, Hertzog, Small, \& Dixon, 1999; Kramer, Bherer, Colcombe, Dong, \& Greenough, 2004) and protects against cognitive decline and dementia (Fratiglioni, Paillard-Borg, \& Winblad, 2004; Ghisletta, Bickel, \& Lövdén, 2006; Lövdén, Ghisletta, \& Lindenberger, 2005). ${ }^{1}$ However, we know little about the mechanisms through which these factors influence cognitive aging. In particular, we do not know whether the beneficial influence of an enriched lifestyle on cognitive change reflects direct effects of mental stimulation on performance or works indirectly by reducing negative effects on cognition (e.g., depression, stress, vascular conditions). To fill this lacuna, researchers must address whether and how plasticity may shape adult cognitive development at behavioral and neural levels

\footnotetext{
${ }^{1}$ Differences in judgment about the strength of the evidence supporting cognitive enrichment effects reflect, in part, differential reliance on crosssectional and longitudinal evidence (Hertzog et al., 2009; Salthouse, 2006). We agree with Hertzog et al. (2009) that cross-sectional data showing a pattern of a stable, rather than increasing, advantage of individuals with favorable lifestyle attributes over individuals with less favorable attributes must not be interpreted as evidence against enrichment effects, as these comparisons are hampered by differential selective attrition and strong scaling assumptions.
} 


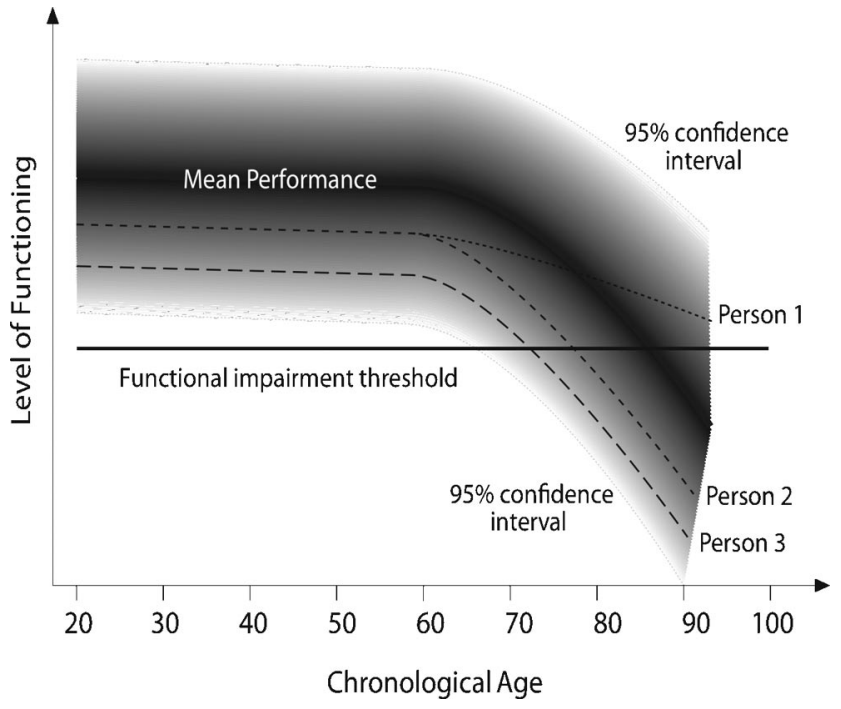

Figure 1. Schematic univariate description of the hallmarks of adult development of fluid intelligence. Performance at a particular point in time displays normal distribution with substantial interindividual differences. Until the seventh decade of life, individuals travel in parallel to a high degree. As indicated by comparison of the trajectories of Person 1 and Person 2, interindividual differences in change are apparent in old age. The age at which functional impairment thresholds (e.g., dementia) are reached is codetermined by level of performance (compare the trajectories of Persons 2 and 3) and change in performance in old age (compare the trajectories of Persons 1 and 2).

of analysis (Baltes \& Singer, 2001; Li, 2003; Lindenberger, Li, \& Bäckman, 2006; Lustig, Shah, Seidler, \& Reuter-Lorenz, 2009).

Plasticity is however rather vague term that permeates contemporary psychology and neuroscience with multiple connotations. Alternative accounts of available findings are difficult to differentiate unless clouds of conceptual confusion are dispersed beforehand (see also Raz, 2007). Here, we propose a theoretical framework for the study of adult cognitive development that lends nuance to and sharpens the conceptual distinctiveness of the term plasticity. We identify general characteristics of adult plasticity and demonstrate the utility of the framework for interpreting findings on several controversial issues: increased frontal brain activation in aging, the effects of cognitive training in adulthood, and the utility of such training for evaluating current evidence on the role of plasticity in cognitive aging. Finally, we derive predictions from our framework that may lead to future research and allow for further testing of its propositions. We hope that the present research synthesis, with its conceptual emphasis, will provide a useful addition to related reviews (Cabeza, 2002; Dinse, 2006; Greenwood, 2007; Hertzog et al., 2009; Jones et al., 2006; Kramer \& Willis, 2002; Li, 2003; Li, Brehmer, Shing, WerkleBergner, \& Lindenberger, 2006; Lustig et al., 2009; Mahncke, Bronstone, \& Merzenich, 2006; Noack, Lövdén, Schmiedek, \& Lindenberger, 2009; Park \& Reuter-Lorenz, 2009; Persson \& Nyberg, 2006; Rajah \& D'Esposito, 2005; Reuter-Lorenz \& Cappell, 2008; Salthouse, 2006; Schaefer, Huxhold, \& Lindenberger, 2006) and help pave the way for a better understanding of adult cognitive development and plasticity.

\section{A Theoretical Framework for the Study of Adult Cognitive Plasticity}

The term plasticity has been used in the behavioral and brain sciences for over a century, with historical milestones contributed by persons such as William James (1890), Eugenio Tanzi (1893), Santiago Ramón y Cajal (1894), and Donald Hebb (1949; for a review of the history of the term, see Berlucchi \& Buchtel, 2009). Over the years, the meaning of plasticity has undergone considerable evolution and proliferation. Despite attempts to render the term more precise (e.g., Konorski, 1948; Mercado, 2008; Paillard, 1976; Will, Dalrymple-Alford, Wolff, \& Cassel, 2008), virtually all types of change in brain and behavior are covered by its contemporary usage (e.g., Baltes, 1987; Baltes, Lindenberger, \& Staudinger, 2006; Brehmer, Li, Müller, von Oertzen, \& Lindenberger, 2007; Buonomano \& Merzenich, 1998; Cooke \& Bliss, 2006; Draganski et al., 2004; Erickson et al., 2007; Greenough, Black, \& Wallace, 1987; Greenwood, 2007; Kelly \& Garavan, 2005; Kempermann, 2006; Kolb, 1995; Li, 2003; Li et al., 2006; Møller, 2006; Pascual-Leone, Amedi, Fregni, \& Merabet, 2005). It is necessary, now more than ever, given the different meanings of the plasticity concept in modern science, to operationally define the term and to sharpen its conceptual distinctiveness in relation to the more encompassing notion of change. Below we outline a framework for the study of adult cognitive plasticity that responds to this necessity.

\section{Plasticity: The Capacity for Reactive Change}

Plasticity revolves around the capacity for change, but the contemporary scientific use of the term is typically reserved for reactive phenomena (e.g., Greenough et al., 1987; James, 1890; Kelly \& Garavan, 2005; Kempermann, 2006; Kolb, 1995; Paillard, 1976; Pascual-Leone et al., 2005; Will et al., 2008). On this view, plasticity reflects a secondary change in response to a primary change in the system. For example, in brain injury, the capacity of the brain to change is considered revealed, not by the primary damage per se, but by the restoring and compensatory (i.e., secondary) reactions to the insult (e.g., Brion, Demeurisse, \& Capon, 1989; Buckner, Corbetta, Schatz, Raichle, \& Petersen, 1996; Chen, Cohen, \& Hallett, 2002; Kopp et al., 1999; Liepert, Storch, Fritsch, \& Weiller, 2000; Ward \& Cohen, 2004). Similarly, when experience (e.g., practicing cognitive or motor tasks) is thought to result in plastic alterations of brain and behavior, it is the secondary responses (e.g., improved performance, structural brain alterations) of the system that are regarded as manifestations of plasticity (e.g., Bengtsson et al., 2005; Draganski et al., 2004; Elbert, Pantev, Wienbruch, Rockstroh, \& Taub, 1995; James, 1890; Kelly \& Garavan, 2005; May et al., 2007) and not the brain representations associated with the particular experience (i.e., the immediate perceptions, thoughts, and actions during practicing). These latter capacities of the brain are typically viewed as starting points of plasticity and considered as characteristics of flexibility in our framework.

\section{Plasticity: The Capacity for Reactive Change in the Range of Functioning}

Flexibility denotes the capacity to optimize the brain's performance within the limits of the current state of functional supply, 
that is, within the current structural constraints imposed by the brain. In particular, flexibility denotes the capacity for representing environmental stimuli via activation of existing (i.e., previously formed) representations, for representing different environmental stimuli differently, and for changing the way a particular stimulus is represented and processed to a previously attainable way. Here, representation denotes the neural activity associated with a particular experience, that is, the neural activity evoked by sensory receptors or by movement and thought (e.g., Mercado, 2008).

We introduce the term flexibility (see also Will et al., 2008) as a synonym to terms such as intelligence, functional capacity, brain functioning, and experience in order to emphasize a simple but important point, the inherently adaptive and variable nature of cognitive and brain functioning. In other words, we note that the cognitive system has a range of existing representational states available and constantly and rapidly adapts to environmental demands by taking different states (cf. Nesselroade, 1991; Piaget, 1980). This notion of a range of performance and function is similar to the concept of functional cerebral space introduced by Marcel Kinsbourne (e.g., Kinsbourne \& Hicks, 1978), which denotes the total repertoire of behaviorally distinct brain states, and to the concept of baseline reserve capacity introduced by Paul Baltes (e.g., Baltes, 1987), which denotes the malleability of cognitive performance by environmental support (e.g., instructions). It also is reminiscent of the notion of vicarious processes in francophone developmental psychology (Lautrey, 2003; Reuchlin, 1978) and relates to the notion of reconfigurability (Mercado, 2008). For example, while listening to or being engaged in a conversation, individuals continuously and rapidly adapt their brain functioning in response to demands on working memory processes (e.g., from spoken sentences with low grammatical complexity to sentences with high complexity) by utilizing the same but more heavily recruited brain processes and by utilizing different constellations of these processes (e.g., D'Esposito et al., 1998; Grossman et al., 2002). In a similar example taken from the perspective of interindividual differences, both a less and a more flexible individual may perform accurately when faced with low demands on working-memory processes, whereas only the more flexible individual may perform accurately when faced with high demands. Similarly, a proficient English speaker listening to a conversation in English will possess greater flexibility in representing the words (e.g., lexically, phonologically, semantically, visuospatially) than will a non-English speaker. Thus, the more flexible individual can handle a larger range of environmental demands.

According to our framework, plasticity denotes the capacity for changes in flexibility, that is, the capacity for changes in the possible range of cognitive performance. In other words, we maintain that reactions and adaptations of the brain to environmental changes do not uniquely define plasticity but rather constitute a fundamental property of experience and a starting point of plasticity. Whereas flexibility-based reactions use existing functional supply, plasticity-based reactions result in alterations of functional supply. The following example illustrates the differences between flexibility and plasticity: A non-English speaker may learn English and in this way increase his or her range of function (i.e., flexibility). This increase in flexibility is a manifestation of plasticity, but the enactment of its outcome, such as the ability to represent English words in different ways and rapidly change between these representations, would be a sign of flexibility. In a similar way, a less flexible individual may increase his or her working memory capacity (e.g., through practice) from being able to maintain four items to being able to maintain six items in store. This increase in working-memory capacity constitutes a manifestation of plasticity, whereas the capacity of being able to rapidly adapt to a wide range of working memory demands does not.

We propose, in summary, that reactive changes based on flexibility meet altered demands with the preexisting range of processing efficiency and knowledge (we return to the knowledge vs. processing efficiency distinction later), whereas plastic reactions meet alterations in demands with the acquisition of new knowledge or altered attainable processing efficiency. Such alterations in knowledge or efficiency change the concurrent range of performance and functioning. ${ }^{2}$

This view is similar to that taken by Paillard (1976; for a discussion, see Will et al., 2008), in which a reactive change is accepted as plastic when it is associated with structural (anatomical) brain changes that have functional consequences rather than when it is associated with changed neural activity in existing pathways. Structural changes may here refer to alterations in the connections allowing for communication between elements of a system or to changes of the constituent elements of the system per se. Changes in the elements of the system include additions and removals of its elements. If we postulate that neurons and glia cells constitute these basic elements, structural changes include, for example, neurogenesis and gliogenesis (for reviews, see Churchill et al., 2002; Jessberger \& Gage, 2008; Kempermann, 2006). Changes in the connections between the elements include changes that allow for some form of rewiring (e.g., new connections, changes in the strength of the connections) of the links among these basic elements. Such structural changes include dendritic and axonal growth (e.g., Hihara et al., 2006), myelination (Fields, 2008), synaptogenesis, and long-term potentiation (LTP) and depression (LTD; Cooke \& Bliss, 2006; Engert \& Bonhoeffer, 1999; Malenka \& Bear, 2004). Changes that affect the system's functioning in more indirect ways (e.g., angiogenesis) also count as structural change. In contrast, transient variations in the system's states, reflecting, for example, action potentials, sodium influx, potassium outflow, and release of neurotransmitters, do not, by themselves, count as anatomical changes in our framework. A similar distinction is found in the literature on cortical map plasticity and experience-dependent changes of receptive fields, or the reallocation of cortical areal extent to modify representations (for reviews, see Buonomano \& Merzenich, 1998; Dinse et al., 1997; Munte, Altenmuller, \& Jancke, 2002; Pascual-Leone et al., 2005; Xerri, 2008). In the emergence of such phenomena, a first phase of rapid and flexible modification of activity in existing pathways is thought to come in the form of unmasking existing connections through, for example, decreased intracortical inhibition of lateral excitatory connections (Jacobs \& Donoghue, 1991). After this initial phase of flexibility-based changes, anatomical changes including, for example, associative synaptic plasticity (i.e., LTP)

\footnotetext{
${ }^{2}$ Piaget (1980; see Chapman, 1988) made a similar distinction, arguing that development alternates between phases of structural change, in which new structures and relations are created, and phases of elaboration, in which the implications of these structures and relations are spelled out.
} 
may follow (e.g., Buonomano \& Merzenich, 1998; Dinse et al., 1997; Pascual-Leone et al., 2005).

In sum, the basic points according to this view are that (a) plastic changes alter brain structure and flexibility, defined as the potential range of performance and functioning available to a person at a given point in time; (b) plasticity and flexibility are distinct; and (c) the critical difference would be lost if the term plasticity was allowed to denote functional changes not accompanied by structural alterations.

\section{Plasticity: The Capacity for Reacting to a Mismatch Between Supply and Demand}

Reports of plastic changes in brain and behavior have in common that primary changes in the range of functional capacity (e.g., brain injury) or in the demands on functional capacity (e.g., cognitive practice), positive or negative, are viewed as the initiating causes of plastic alterations. A key proposition in our framework is that such changes induce plastic alterations only to the extent that they result in a mismatch between supply in the form of the functional capacity of the system and the environmental demands that operate in the system through experience (see also Bäckman \& Dixon, 1992). Thus, manifestations of plasticity are reactions to a materialized supply-demand mismatch and not to changes in demand or supply per se.

The mismatch comes in two principal ways: higher demands than the available capacity or higher available capacity than the current demands. A study by Draganski et al. (2004) illustrates both of these forms of mismatch and possible resulting manifestations of plasticity. Using magnetic resonance imaging (MRI) and voxel-based morphometry, Draganski et al. studied gray matter of younger adults before, immediately after, and 3 months after termination of a 3-month period of learning how to juggle. Results showed gray-matter increases in brain regions known to be involved in the coordination of motor functions. These alterations had almost returned to baseline 3 months after the termination of training. Though the exact biological nature of these alterations is unknown, these findings can be interpreted as reactions to increased environmental demands on insufficient functional supply during training. That is, the juggling practice entails an increased use of processes related to visuomotor coordination that increase the demands on functional supply. After juggling practice is terminated, another mismatch is induced in the sense that experienced demands are lower than the functional supply, and brain structures adapt by getting rid of unnecessary functional supply. Such an interpretation is consistent with evidence showing atrophied neural structure induced by loss of peripheral receptors (e.g., Draganski, Moser, \& Lummel, 2006) and altered metabolism in animals induced by impoverished environments (e.g., Beaulieu \& Colonnier, 1989; Diamond, Lindner, Johnson, Bennett, \& Rosenzweig, 1975).

We maintain that the principal driving force of the different forms of plastic alterations is not the primary changes per se (e.g., altered experience, brain injury) but the mismatch between functional capacity and experienced demands that these changes induce. Note also that we regard the supply-demand mismatch as a useful conceptual model for identifying, analyzing, and optimizing the direction and magnitude of the impetus for plastic changes and, therefore, as a model that allows for predicting the likelihood and nature of a plastic response. However, this model is not proposed to constrain the exact biological and cognitive mechanisms underlying different manifestations of plasticity.

The mismatch model fits the typical learning curve of initially rapid but then diminishing increases in performance approaching an asymptotic level. That is, the model holds that functional supply initially responds to the increased demands; later, when supply meets the demands, further impetus for change is lost. From this perspective, levels of cognitive performance that are stable over some time scale can be viewed as dynamic equilibrium states of reactions to changes in the overall landscape of demands and supplies.

We further propose that the current range of flexibility (i.e., functional supply), which is co-constructed by genetic influences and past manifestations of plasticity (Baltes et al., 2006; Garlick, 2002; Li, 2003; Mercado, 2008), will determine the degree and nature of the mismatch in two related ways (cf. Norman \& Bobrow, 1975; Piaget, 1980). First, if the system can effortlessly respond to a specific demand with existing flexibility, no mismatch arises. For example, teaching basic English vocabulary to individuals proficient in English or administering an easy working memory task that can be performed without effort will induce neither a supply-demand mismatch nor any plastic alterations. Second, if environmental demands are not within the current range of flexibility, a mismatch is absent as well. For example, humans may not show substantial plastic changes in response to ultrasound (although a bat that can experience the sound may do so). In less extreme cases, such as when an individual is faced with a workingmemory task that exceeds the capacity limits, no mismatch may occur because the individual may give up or apply taskinappropriate processes. The individual may thus experience the task differently than other individuals who have a larger range of flexibility. In other words, demands need to be within the range of functional capacity enabled by flexibility in order to trigger plasticity. In this sense, the current range of flexibility limits the capacity for reactive change. Mismatches must be located between these two extremes (e.g., a too easy vs. a too difficult task) to trigger and direct plastic changes. This reasoning is implied in the design of cognitive-training studies with groups assigned to adaptive task-difficulty conditions and a placebo control group assigned to low task-difficulty training. The idea is bolstered by findings of intervention-related effects on cognitive performance after training in such studies (e.g., Klingberg et al., 2005; Persson \& Reuter-Lorenz, 2008).

To put it differently, we maintain that the system needs to experience a supply-demand mismatch to be able to act upon it (Bäckman \& Dixon, 1992; Piaget, 1980). In this sense, flexibility determines plasticity in interaction with environmental stimuli. This mismatch model contrasts with models identifying interindividual differences in intelligence (i.e., flexibility) as interindividual differences in plasticity (e.g., Garlick, 2002). Although such models have considered plasticity and the environment when explaining the development of intelligence, the mismatch model adds to this view by stating that an individual's developmental trajectory of intelligence (see Figure 1) can in principle be affected by the individual's intrinsic plasticity and the environment in interaction with the individual's concurrent flexibility. Moreover, our model does not come with the prediction that greater flexibility always leads to a larger (or smaller) supply-demand mismatch and 
a stronger (or weaker) force driving plastic changes. Instead, the magnitude of the mismatch depends on the match between current functioning of the system and the environment. For example, an individual with low working-memory capacity may show larger performance gains from training on a nominally easy working memory task (i.e., experience a larger mismatch between supply and demand) than a person with higher working-memory capacity, as the latter can easily perform the task and therefore does not experience a supply-demand mismatch. However, in a nominally very difficult task, a person with lower working-memory capacity may be in a situation allowing for less impetus for change than experienced by a person with high working-memory capacity. The person with low capacity may not be able to perform the task sufficiently well to experience the environmental demands on the functional supply. In sum, the mismatch model predicts that the current range of flexibility determines whether a given environmental challenge induces plasticity and states that the key factor triggering a plastic response is the relative mismatch the system is experiencing.

\section{Plasticity: A Sluggish Capacity}

The presence of experienced supply-demand mismatches must be a rule rather than an exception for a system characterized by variable brain functioning, behavior, and environment. Always responding to these mismatches with plastic (structural) changes, rather than with utilization of the range of function supported by a priori faculties, would be functionally and economically maladaptive. A neurocognitive system under permanent renovation would not develop a coordinated scheme of habits and would constantly consume large amounts of energy. In addition, to remain efficient, the system must be stable and maintain established skills. That is, a supply-demand mismatch faces a system characterized by inertia and sluggishness in response to mismatches, and some unknown duration of the supply-demand mismatch must be reached if an adaptive system is to be forced to trade the goal of stability for that of plasticity (Bäckman \& Dixon, 1992; Piaget, 1980). The degree of sluggishness of responses to a mismatch may differ among different manifestations of plasticity, probably in part as a function of the metabolic costs of their implementation. For example, whereas gliogenesis and growth of capillaries are phenomena that may develop over months, synaptogenesis and structural changes associated with LTP may develop over hours, minutes, or seconds. Manifestations of plasticity are too diverse to allow for a unified definition of the degree of sluggishness in an absolute time metric, though the notion can perhaps be further specified in terms of the relative duration of the plasticity-inducing change and the development of the resulting plastic change (which must take more time). That is, the phase of development of a plastic response must be longer than the time it takes to induce the initial and primary plasticity-inducing change in demand or supply, so that this developmental phase will be interrupted if the primary changes are not repeated or otherwise prolonged but are discontinued or replaced by other supply-demand mismatches. This notion shares similarities with the view requiring the resulting changes to be longer lasting than their cause to warrant the label plastic (Paillard, 1976; for a discussion, see Will et al., 2008).

We propose, in sum, that mismatches need to be prolonged to overcome the inertia and sluggishness of plasticity and to push the system away from its current dynamic equilibrium state. Figure 2 schematically summarizes this principle. Situations with a mismatch between functional supply and experienced environmental demands caused by primary changes in demand (e.g., cognitive training; see Figure 2A) and by primary changes in functional supply (e.g., brain injury; see Figure 2B) are depicted separately. Functional supply (i.e., the structural constraints imposed by the brain) allows for range of performance and functioning. Flexibility denotes the capacity to optimize the brain's performance within the limits of the current state of functional supply. Due to the sluggishness of plasticity, structural supply optimizes its support for function to demand (i.e., use of functional supply; black line) that is averaged over some time period. Mismatches need to be prolonged to overcome the inertia and sluggishness of plasticity and to push the system away from its dynamic equilibrium. Deviations in demand that are within the current range of functional supply constitute the mismatch that provides the impetus for change (green $=$ negative mismatch; demand is higher than the demand for which structural supply is optimized; red = positive mismatch; demand is lower than the demand for which structural supply is optimized).

\section{Plasticity: Limited Intrinsic Capacity}

We conceive of supply-demand mismatches as a necessary but not sufficient condition for plastic change. In addition, plasticity is constrained by the intrinsic potential for plastic change in the system, as determined by previous manifestations of plasticity, genetic influences, and primary environmental influences on, for example, level of nerve growth factors and energy supply through vascular integrity (for review, see Mercado, 2008). Therefore, even if the relative mismatch is equally large across different individuals, we may expect individual and age differences in the magnitude of manifestations of plasticity, such as performance increments from practice. Moreover, not all mismatches can be reacted to and closed. The supply-demand mismatch model thus cannot fully predict whether and how plasticity is manifested, but it is useful for identifying the magnitude and nature of the impetus for plastic changes.

\section{Manifestations of Plasticity: The Distinction Between Process and Knowledge}

Plasticity manifests itself in several forms that share the basic principles outlined above (see also Will et al., 2008). Our framework highlights a distinction that we consider important for understanding cognitive development: plasticity that alters representations (i.e., knowledge, memory) versus plasticity that alters processes and their efficiency. The distinction between mental representations (or knowledge) and the processes (or mental operations) that transform and manipulate representations is central to cognitive psychology and is often an important part of introductory chapters in cognitive-psychology textbooks (e.g., Gazzaniga, Ivry, \& Mangun, 2002). Here, cognitive processes come in many forms that operate on mental content in qualitatively different ways to transform it.

The distinction between process and knowledge is also at the core of most two-component theories of intellectual development (Lindenberger, 2001), such as the theory of fluid versus crystal- 
A

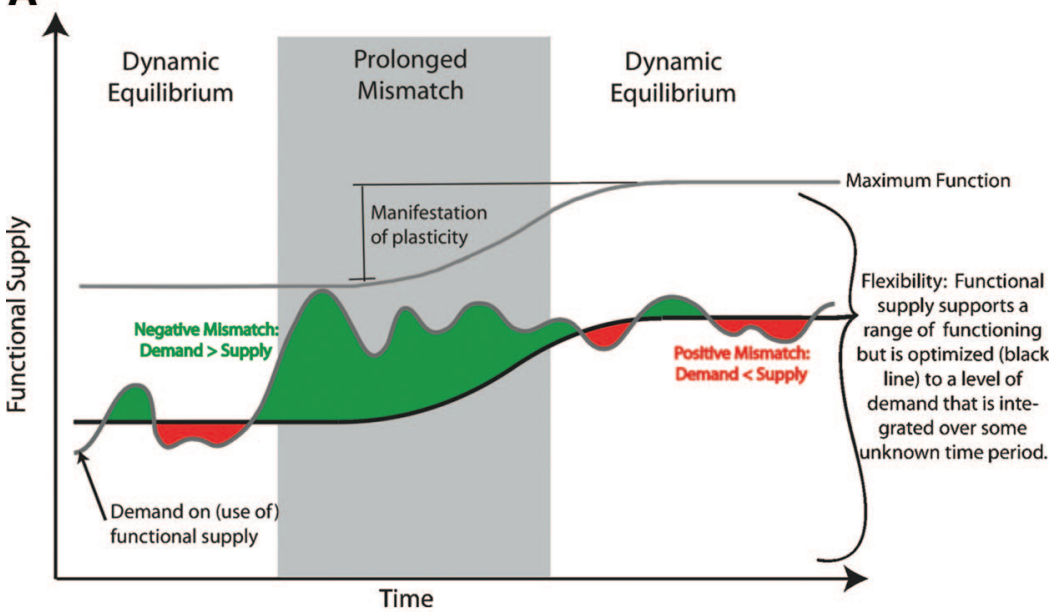

B

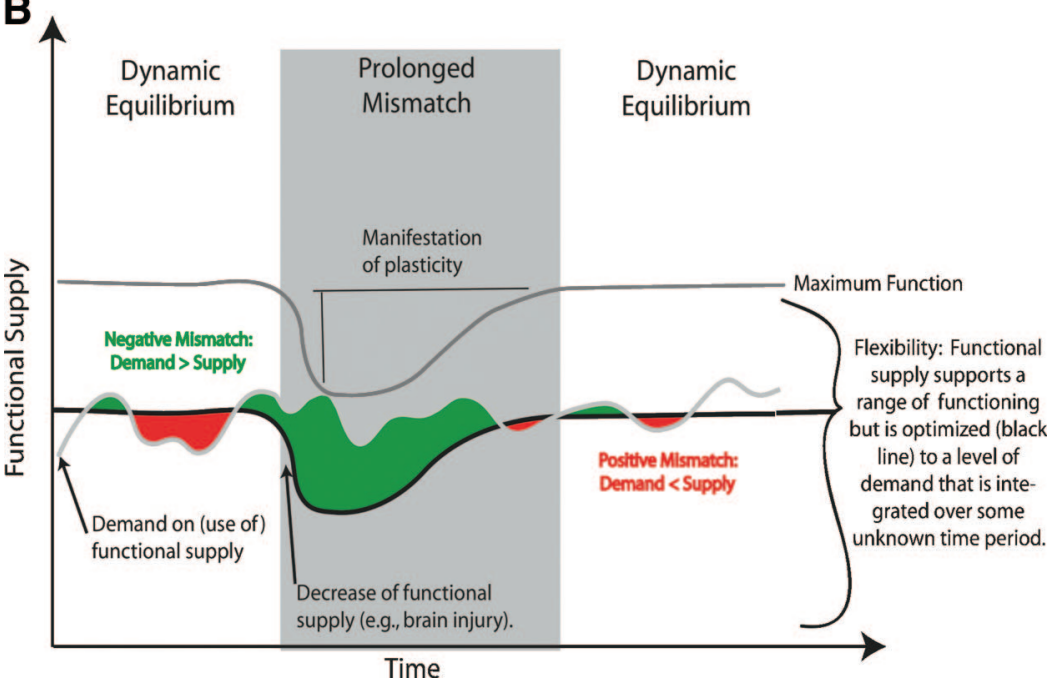

Figure 2. Schematic model of a mismatch between functional supply and experienced environmental demands caused by primary changes in demand (Figure 2A) and primary changes in functional supply (Figure 2B). Functional supply (i.e., the structural constraints imposed by the brain on function and performance) allows for range of performance and functioning. Flexibility denotes the capacity to optimize the brain's performance within the limits of the current state of functional supply. Due to the sluggishness of plasticity, structural supply optimizes its support for function to a level of demand (i.e., use of functional supply) that is averaged over some unknown time period, and mismatches need to be prolonged to overcome the inertia and sluggishness of plasticity and to push the system away from its dynamic equilibrium. Deviations in demand that are within the current range of functional supply constitute the mismatch that constitutes the impetus for change. Alternatively, decreases in functional supply combined with unaltered demand (Figure 2B), decreases in demands (not shown), or increases in supply may constitute impetus for change through the same principle of a mismatch between demand and supply.

lized intelligence (Horn \& Cattell, 1966) or of the mechanics and pragmatics of cognition (Baltes, 1987). These theories build on the observation that abilities composed of procedural and declarative knowledge and abilities composed of relatively content-invariant cognitive processes (e.g., perceptual speed, reasoning) form different factors and display different developmental trends across the lifespan. Fluid intelligence displays more pronounced age-related decline than does crystallized intelligence (e.g., McArdle, FerrerCaja, Hamagami, \& Woodcock, 2002; Rönnlund et al., 2005; for review, see Lövdén \& Lindenberger, 2005) and is more tightly associated with biological integrity (Lindenberger \& Baltes, 1997).
The distinction between processes and knowledge is also evident, though more implicitly, in contemporary cognitive neuroscience of aging. Losses in gray-matter volume (Raz et al., 2005), white-matter microstructure (Madden, Bennett, \& Song, 2009; Sullivan \& Pfefferbaum, 2006), concentrations of neurotransmitters such as dopamine (Bäckman, Nyberg, Lindenberger, Li, \& Farde, 2006), and cerebrovascular integrity (Farkas \& Luiten, 2001; Raz et al., 2005) are investigated as causes of reductions in processing efficiency, which affect the representation and retrieval of existing knowledge as well as the acquisition of new knowledge. Thus, loss of knowledge is 
regarded as a consequence rather than a cause of cognitive aging (Ghisletta \& Lindenberger, 2003).

We propose that the study of adult cognitive plasticity may benefit from acknowledgment that plasticity may also allow for the alteration of processing efficiency in adulthood and aging, and not only for the acquisition of knowledge. For example, increased use of workingmemory processes may result in a supply-demand mismatch that is reacted to by alterations in the density of dopamine receptors (McNab et al., 2009). Such alterations may affect working-memory processes in a way similar to the administration of dopaminergic agonists (Mattay et al., 2000): by improving performance through affecting processing efficiency and not through acquiring knowledge. That is, plasticity may alter an adult's possible range of performance by affecting representations, processing efficiency, or both.

Acquisition of knowledge makes the system more flexible because it has more existing and distinct representations of the environment and more ways to achieve a particular behavioral outcome. For example, a non-English speaker may learn English and in this way increase his or her range of function (i.e., flexibility). Improvement of processing efficiency makes the system more flexible because it has a larger range of performance and higher limits to performance. For example, both a less and a more flexible individual may maintain three items in working memory, whereas only the more flexible individual may maintain nine. Thus, knowledge and processing efficiency are two facets of flexibility that could be altered by plasticity.

In the next section, we demonstrate that this distinction between alterations of representations and alterations of processes, as well as the other central tenets of our framework, may help us interpret controversial findings in the behavioral neuroscience of aging, evaluate the current evidence on the role of plasticity in adult cognitive development, and motivate and guide future research.

\section{Applications of the Theoretical Framework}

We provide two examples of patterns of empirical data to which our framework can be applied. The first example could potentially be related to the situation depicted in Figure 2B, where a manifestation of plasticity is induced by a primary change in functional supply (e.g., brain injury). The second example deals with the situation shown in Figure 2A, where manifestation of plasticity is induced by a primary change in environmental demands.

\section{Increased Prefrontal Cortex Activation in Aging}

In neuroimaging work on higher order cognition (e.g., working memory and episodic memory), increased activity in the prefrontal cortices, particularly in dorsolateral areas, has sometimes been observed in older adults, often along with decreased activity in the ventrolateral prefrontal cortex or in posterior brain regions (e.g., Cabeza et al., 2004; Davis, Dennis, Daselaar, Fleck, \& Cabeza, 2008; Grady et al., 1994; Grady, McIntosh, \& Craik, 2003; Grossman et al., 2002). Sometimes this pattern comes in the form of increased activity in the prefrontal cortex contralateral to the region primarily activated in younger adults (Bäckman et al., 1997; Cabeza et al.,1997; ReuterLorenz et al., 2000; for reviews, see Cabeza, 2002; Greenwood, 2007; Park \& Reuter-Lorenz, 2009; Persson \& Nyberg, 2006; Rajah \& D'Esposito, 2005). Figure 3 depicts examples of these findings.

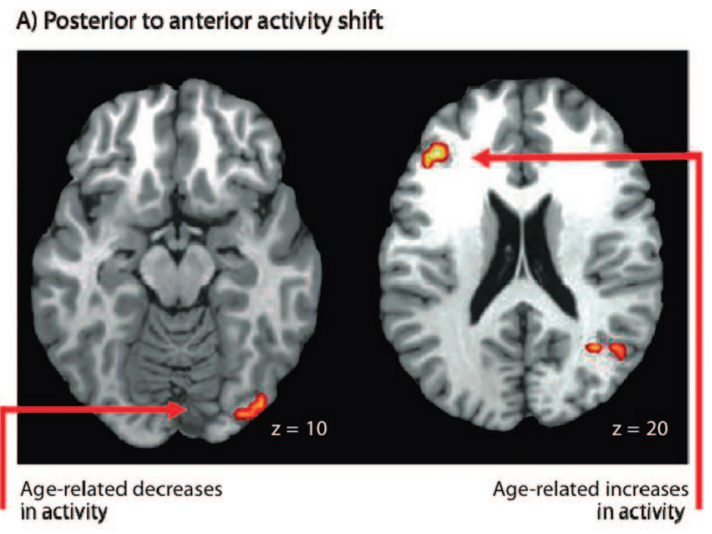

B) Increased bilaterality in prefrontal cortex

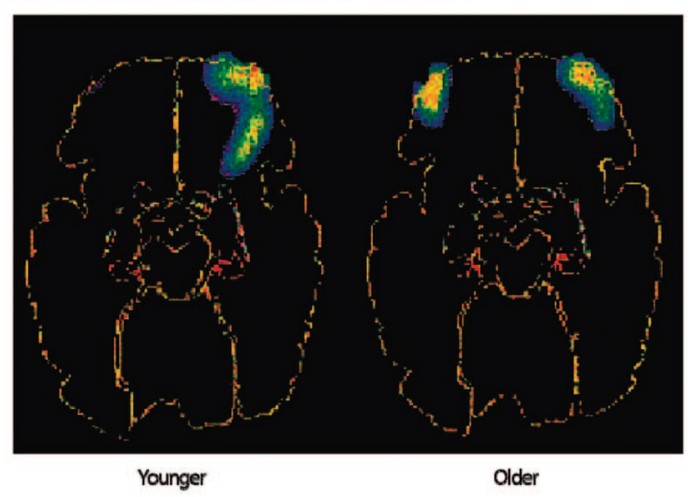

C) Ventral to dorsal activity shift in prefrontal cortex

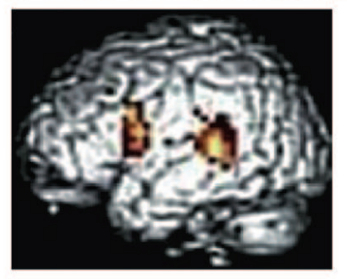

Decreased activity in poor Older performers

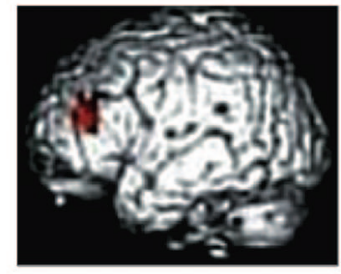

Increased activity in poor Older performers
Figure 3. A: Results show findings from Davis et al. (2008) indicating increased activity in dorsolateral prefrontal cortex and decreased activity in occipital cortex with aging during episodic retrieval and a perceptual task. B: More bilateral activity emerges in aging during episodic retrieval. Results show a pattern of more bilateral activity in old age during a word-stem cued-recall task. Adapted from "Brain Activation in Young and Older Adults During Implicit and Explicit Retrieval," by L. Bäckman, O. Almkvist, J. Andersson, A. Nordberg, B. Winblad, R. Reineck, \& B. Långström, 1997, Journal of Cognitive Neuroscience, 9, p. 386. Copyright 1997 by MIT Press. C: Redistribution of activity from ventral to dorsal prefrontal cortex is common for episodic encoding and working memory tasks. Results show increased activity in dorsolateral prefrontal cortex but decreased activity in ventrolateral prefrontal cortex for healthy older people displaying poor performance during a comprehension/working memory task (Grossman et al., 2002). 
Primary or secondary change? As we start carving out the different interpretations of this pattern of findings and appraise the evidence for them, our framework's first distinction between primary changes and reactive changes will be useful. In particular, the notion that increased prefrontal activity is a direct associate of age-related negative changes in functional supply should be contrasted with the notion that increased activity is a response of the system to a supply-demand mismatch induced by these changes (see also Cabeza, 2002; Park \& Reuter-Lorenz, 2009). The possibility that increased prefrontal activation could be a direct consequence of primary negative changes is supported by at least two lines of research. First, computational modeling has suggested that reductions in dopamine with aging (Bäckman et al., 2006) may lead to increased neural noise that may in turn lead to less distinct cortical activation patterns in aging ( $\mathrm{Li} \&$ Lindenberger, 1999; Li \& Sikström, 2002; Li et al., 2006). Second, reductions in whitematter integrity during aging (Madden et al., 2009; Sullivan \& Pfefferbaum, 2006) are associated with increased bilateral activity in the prefrontal cortex during cognitive activity (Persson et al., 2006). Decreased inhibitory efficiency of the contralateral hemisphere caused by such white-matter degradation have been suggested as a mechanism that may produce age-related activation differences (O'Sullivan et al., 2001). In the competing account, these primary age-related changes, or other negative changes such as decreased gray-matter volume (e.g., Greenwood, 2007; Park \& Reuter-Lorenz, 2009), are proposed as a primary cause of a supply-demand mismatch (see Figure 2B) that is responded to by recruitment of alternative cortical areas.

Whether or not increased activity in the prefrontal cortices is beneficial to performance may separate these two accounts. Primary negative changes should not be associated with higher performance, but flexibility- or plasticity-based reactions to a mismatch induced by decline in functional supply should. Several imaging studies have shown positive associations between performance and increased activity in the prefrontal cortices among older adults (Cabeza, Anderson, Locantore, \& McIntosh, 2002; Davis et al., 2008; Rosen et al., 2002; Rossi et al., 2004; but see Erickson et al., 2007; Persson et al., 2006). For example, Rossi et al. (2004) used repetitive transcranial magnetic stimulation (rTMS) to transiently interfere with processing in the left or the right dorsolateral prefrontal cortex during visuospatial recognition memory in younger and older participants. Results showed that among the young adults, rTMS of the right dorsolateral prefrontal cortex interfered more than left-sided rTMS did with retrieval. In older adults, left and right rTMS had similar effects on performance. These results suggest that the additional left-sided activation in older adults during retrieval was beneficial to performance, and this finding is difficult to reconcile with the notion that increased prefrontal activations are exclusively restricted to primary manifestations of age-related decline.

Flexibility or plasticity? Our framework suggests that, if we were to accept the evidence in favor of a reactive change, at least as a plausible account of some of the findings in some experimental situations, we should address whether this response is based on flexibility or plasticity. In other words, is the supply-demand mismatch, which is initiated by primary negative changes in functional supply, responded to by the use of existing resources only, or does the response come in the form of improved range of performance and functioning? That is, is the change purely func- tional (i.e., based on flexibility), or is it associated with structural changes (i.e., plasticity)? In our judgment, the available evidence is insufficient to provide a clear answer to this question. However, a possible route for examining this issue is to utilize increasing levels of task difficulty as a simulation of adult age differences and examine younger adults' responses to such manipulations. If rapid changes in activation patterns in response to altered demands are similar to the pattern of age differences in the engagement of the prefrontal cortices, an account based on flexibility is plausible. That is, plastic changes are more sluggish than changes based on flexibility and need more prolonged mismatches to develop (see Figure 2).

The available evidence on this issue is consistent with the flexibility account (see also Park \& Reuter-Lorenz, 2009). For example, Banich (1998) showed that younger adults engage in more bilateral processing during performance of tasks with higher complexity. Older adults display similar effects that appear at lower nominal task demands than for younger adults (ReuterLorenz, Stanczak, \& Miller, 1999). In addition, younger adults add recruitment of the dorsolateral prefrontal cortex to the recruitment of the ventrolateral prefrontal cortex when working memory load is increased (Rypma \& D'Esposito, 2001). Thus, this evidence suggests that age-related compensation based on flexibility is more parsimonious than compensation based on plasticity as an account of increased prefrontal activations in aging (see also Park \& Reuter-Lorenz, 2009).

However, these findings do not exclude that increased prefrontal activity in aging may be supported by plasticity. The lack of evidence does not mean an absence of a phenomenon. Moreover, age-related and flexibility-based alterations of activity patterns in response to decreased functional supply that is combined with unaltered environmental demand (see Figure 2B) may induce a prolonged mismatch in prefrontal brain regions that have not been involved as frequently in task performance during earlier phases of ontogeny. Such changes in cortical processing may in turn serve as an impetus for plastic change (Greenwood, 2007), which may lead to plastic change if the older adult possesses residual intrinsic capacity for plastic change. Such a dynamic chain of events is probably responsible for the related phenomenon of cortical map plasticity (for reviews, see Buonomano \& Merzenich, 1998; Dinse et al., 1997; Munte et al., 2002; Pascual-Leone et al., 2005; Xerri, 2008). In this phenomenon, a first phase of rapid and flexible modification of activity in existing pathways may be followed by associative synaptic plasticity as a result of a supply-demand mismatch stemming from altered functional demands on the infrastructure (e.g., Buonomano \& Merzenich, 1998).

Evidence on the issue of whether plasticity may be involved in, or result from, the phenomena of increased prefrontal activation in aging would profit from longitudinal studies with larger samples measured on changes in structure (e.g., gray-matter volumes, white-matter microstructure), molecular scale (e.g., receptor densities), and function (e.g., activation patterns), together with changes in performance (see also Greenwood, 2007). By leveraging the assumption that plastic changes are more sluggish than changes based on flexibility, modern methods capable of analyzing dynamic lead-lag patterns in longitudinal data (e.g., McArdle, 2001; for an application, see Lövdén et al., 2005) may allow examination of the temporal dynamics of primary and secondary aging. Here, the plasticity interpretation would predict time- 
ordered sequences of empirical data on older adults, such that longitudinal increases in prefrontal activity during workingmemory performance would be preceded and predicted by, for example, lower levels of dopamine receptor density as imaged with positron-emission tomography (for a review, see Bäckman et al., 2006) and that stronger increase in prefrontal activity would predict more positive subsequent long-term development of dopamine receptor densities.

\section{Improvement of Cognitive Performance From Cognitive Training in Adulthood and Old Age}

To entertain the hypothesis that plasticity shapes cognitive aging, one needs to show that cognitive performance is indeed plastic in adulthood and old age. Among several lines of investigation, research on the effects of cognitive training has a long history of addressing this research question. Below we review this literature with a focus on demonstrating that our framework is applicable for interpreting and evaluating the extant findings.

In attempting to improve primarily episodic memory and reasoning performance, a body of studies teaching younger and older adults tailored cognitive strategies (e.g., mnemonic strategies such as the method of loci) has revealed that cognitive training can produce performance increments in both younger and older adults. Training-induced performance gains decrease with adult age, and they generalize to some extent to tasks in which the trained strategy can be applied (e.g., Ball et al., 2002; Baltes, DittmannKohli, \& Kliegl, 1986; Baltes \& Kliegl, 1992; Baltes \& Willis, 1982; Craik et al., 2007; Kliegl, Smith, \& Baltes, 1989; Stigsdotter Neely \& Bäckman, 1995; Stuss et al., 2007; Willis, Blieszner, \& Baltes, 1981; Wood \& Pratt, 1987; Yesavage, 1984; for reviews, see Baltes \& Lindenberger, 1988; Barnett \& Ceci, 2002; Noack et al., 2009; for meta-analysis, see Verhaeghen, Marcoen, \& Goossens, 1992). More recent studies have administered practice on tasks targeting a variety of cognitive processes, such as working memory (Buschkuehl et al., 2008; Dahlin, Stigsdotter Neely, Larsson, Bäckman, \& Nyberg, 2008; Jaeggi, Buschkuehl, Jonides, \& Perrig, 2008; Li et al., 2008; Olesen, Westerberg, \& Klingberg, 2004), executive functions (Bherer et al., 2005; Karbach \& Kray, 2009; Kramer, Larish, \& Strayer, 1995), recollection (Jennings, Webster, Kleykamp, \& Dagenbach, 2005), interference resolution (Persson \& Reuter-Lorenz, 2008), or a combination of processes from various domains of functioning (Basak, Boot, Voss, \& Kramer, 2008; Mahncke, Connor, et al., 2006). Like the strategybased studies, these practice-oriented studies have revealed improvements on practiced tasks in both early and late adulthood. More important, several of the practice-oriented studies have reported transfer of training gains to untrained tasks that to various degrees are representationally unrelated to the trained tasks, because performance on these tasks depends on different strategies, response mappings, and perceptual expertise (e.g., Basak et al., 2008; Buschkuehl et al., 2008; Dahlin et al., 2008; Jaeggi et al., 2008; Jennings et al., 2005; Karbach \& Kray, 2009; Olesen et al., 2004; Persson \& Reuter-Lorenz, 2008).

The available evidence needs to be judged in the light of methodological limitations that characterize, in one way or another, most of the practice-oriented studies conducted so far. Such limitations include small and select samples, small effect sizes, lack of appropriate control group comparisons, and effects on select transfer tasks only (see also Moody, 2009; Sternberg, 2008).
We would like to demonstrate, notwithstanding these limitations, how the application of our framework helps in evaluating the conceptual significance of positive transfer to untrained tasks.

The issue of transfer of learning has a long-standing history in cognitive and educational psychology. It dates back to the debate between proponents of the doctrine of formal schooling, who argued that schooling should exercise broadly applicable mental faculties, and researchers underscoring the specificity of learning, who argued that training leads to changes in the knowledge base relevant to the trained task (Thorndike, 1906; Thorndike \& Woodworth, 1901; see also more recent learning theories, such as that of Logan, 1988). The main argument for the importance of assessing transfer of learning is, however, the practical significance of generality (e.g., Barnett \& Ceci, 2002; Schmidt \& Bjork, 1992): If effects of schooling are to be maximized, the acquired knowledge should be widely applicable (e.g., in different situations over time). By analogy, if cognitive interventions are effective, improvements should affect many domains of functioning relevant for maintaining competence and autonomy in everyday life.

We agree that broad applicability of improvements is important and note that useful taxonomies and dimensions of generality have been proposed (e.g., Barnett \& Ceci, 2002; Noack et al., 2009) and applied to adult cognitive plasticity (Zelinski, 2009). However, we posit that the scientific tool of assessing transfer is not restricted to probing generality. If generality of the effectiveness of cognitive training and practice were the only methodological concern in cognitive training studies, assessing transfer would not be strictly necessary. For example, assume that adults practice workingmemory tasks and show improvements in performing these tasks (e.g., Dahlin et al., 2008: Jaeggi et al., 2008; Olesen et al., 2004). If generality were the only concern, improvements in workingmemory performance, along with findings that working-memory performance is highly predictive of other cognitive functions as well as outcomes in academic, professional, and everyday life context (e.g., Baddeley, 2003; Conway, Kane, \& Engle, 2003; Kyllonen \& Christal, 1990), would be sufficient cause to claim that the intervention has broad effects. However, as has long been noted, this reasoning is faulty because improvements in task performance are composed of different components, some of which (e.g., development of effective strategies, memorizing response mappings, and perceptual expertise) are not operationally defining improvements in the efficiency of working-memory processes. Thus, the observed performance increments on the trained tasks do not necessarily imply that competencies in other cognitive functions in and out of the laboratory have been improved. Transfer of training can be used to address this concern. It can be viewed as a general measurement tool with which to trace improvements in performance to some aspect of task execution that is of interest for one reason or the other. According to the basic logic of transfer assessment, we can observe effects on a particular transfer task only if it shares some commonality with the trained task, a commonality that also has changed as a function of the intervention (cf. Thorndike, 1906; Thorndike \& Woodworth, 1901).

Dahlin et al. (2008) recently applied the commonality logic of transfer assessment to behavioral neuroscience. In this study, younger and older adults practiced updating in working memory over 5 weeks. Task-specific performance increases, as observed on a letter memory task, were substantial. For younger adults, transfer of improvements was observed on an n-back task but not on a 
Stroop task. Functional neuroimaging during performance of these three tasks before and after training revealed brain activation overlaps among these tasks at baseline. Most important, changes in striatal activity (which has been linked to updating; Hazy, Frank, \& O'Reilly, 2006) were observed only for the trained task and the transfer task showing improvements (n-back). Thus, this study illustrates the logic that transfer will be observed only if some commonality (e.g., a common brain substrate of performance) is (a) shared between the trained task and the transfer task and (b) has changed as a function of training (for a similar demonstration with behavioral measures, see Persson \& Reuter-Lorenz, 2008).

A statistical analogue of this commonality logic is used in confirmatory factor analysis. Here, a latent (unobservable) variable, or target construct, is operationally defined with several tasks, which are assumed to be influenced to some degree by the target construct but that are heterogeneous on as many other performance-influencing factors as possible (Little, Lindenberger, $\&$ Nesselroade, 1999). The common variance of such a set of tasks is then extracted as a latent factor and interpreted as reflecting individual differences in the target construct. This allows for extracting performance "at the latent level," representing the variance components that are common to the set of tasks indexing a given target construct.

If assessment of transfer is viewed as a general measurement tool for isolating change in some aspect of performance, and not as a tool for assessing generality of change per se, researchers are forced to operationally define which aspect of task performance is of interest. To this end, they need a theory of the ways in which performance is assumed to change in response to the supplydemand mismatch induced by the training regime. In this context, our theoretical framework can be applied.

Our framework proposes that performance may increase because the person has acquired knowledge relevant for the particular task, has improved in task-relevant processing efficiency, or both. Improvements in performance that can be attributed to knowledge acquisition include declarative memory and knowledge (e.g., problems of this geometric kind can be solved by applying the Pythagorean theorem), learned stimulus-response mappings (e.g., yes response $=$ green button), and development of perceptual expertise. The development of strategies (test-taking strategies, mental strategies) also belongs to this category and can be viewed as the acquisition of knowledge that capitalizes on flexibility to improve performance. In the case of mental strategies, the assimilated instruction or self-discovery that some particular combination of processes may be used to solve a particular task with better performance (e.g., imaging words that are to be remembered rather than rehearsing them) constitutes an improvement in performance based on knowledge acquisition. Improvements in process efficiency are, by definition, improvements in the efficiency of one or more cognitive processes (e.g., updating in working memory, perceptual speed, vigilance, associative binding) that generalize over the content to which the process is applicable.

In our view, past interpretations of transfer effects and debates on the extent to which learning transfers to untrained tasks are blurred by confusing the difference between alterations in process efficiency and the acquisition of knowledge with the issue of generality. In particular, dimensions of generality (e.g., time, context) are conceptually orthogonal to the process-knowledge distinction. Both knowledge and processes can be more or less broadly applicable. For example, a cognitive strategy for remembering information may be more or less general. Some strategies, such as the strategy to replace numbers with letters and form words with which to remember PIN codes better (Derwinger, Stigsdotter Neely, Persson, Hill, \& Bäckman, 2003), may be of relevance in relatively few contexts (i.e., when remembering numbers), whereas other strategies for remembering information, such as using imagery, may improve performance in a larger number of situations.

Processes may also be more or less relevant in different contexts, including those of daily life. For example, whereas improvement in working memory or associative memory processes may affect many types of cognitive functions and have broad relevance in everyday settings, improvements of auditory discrimination processes may be of more limited significance across different situations. The point that the distinction between processes and knowledge is in principle orthogonal to generality does not exclude the possibility that alterations in processing efficiency may often have a larger potential than alterations in knowledge to be widely applicable. Representations (i.e., knowledge and memories) may be easier to alter and gain-and we know that this type of plasticity is preserved to a considerable extent in older age- - but acquired knowledge may generally be of relatively limited applicability. In contrast, processing efficiency may be more difficult to alter (e.g., due to higher metabolic costs) and changes may occur in a more sluggish manner, but the function may often be more widely applicable.

Whereas most early cognitive training studies (e.g., Baltes et al., 1986) and studies in the field of educational psychology (e.g., Barnett \& Ceci, 2002) have used the assessment of transfer effects for the purpose of evaluating the generality of improvements, the recent literature shows a shift toward using the transfer tool as a way to operationally define improvements in processing efficiency (e.g., Karbach \& Kray, 2009; Persson \& Reuter-Lorenz, 2008). This shift is also reflected in a change in training protocols, from teaching cognitive strategies to repeated practice on tasks tapping theoretically defined processes (e.g., updating, task switching). Investigating adult cognitive plasticity in aspects of processing efficiency, such as updating in working memory, processing speed, and inhibition, has practical relevance and also informs about the modifiability of age-related cognitive decline (see also Mayr, 2008). Hence, the apparent sway of the pendulum from representation to process in adult cognitive intervention work has important benefits.

Note, however, that the shift from assessing transfer to address generality of training gains to addressing whether processing efficiency has been improved poses new challenges. Generality can be addressed without much of a theory and without much methodological effort. For example, through application of taxonomies of transfer, based on content and context (Barnett \& Ceci, 2002) or the structure of human intelligence abilities (Noack et al., 2009), common frameworks for evaluating the effectiveness of interventions through the lens of generality can be achieved. However, concluding that cognitive interventions have resulted in alterations in processing efficiency means that higher demands must be placed on designing appropriate transfer tasks. This is so because the logic of assessing transfer to make conclusions about alterations in processing efficiency is based on exclusion. Tasks, in conjunction with appropriate placebo control groups, must be 
designed so that all performance changes that can be attributed to knowledge acquisition (e.g., development of strategies, perceptual expertise) can be excluded as a cause of performance changes. This requires, for example, a good understanding of the space of possible effective strategies in the cognitive tasks used in training and the design of transfer tasks in which these strategies have been demonstrated to be ineffective or impossible to apply.

In general, our framework thus provides a rather critical lens through past studies showing transfer effects can be reviewed. For example, one of the most impressive pieces of evidence for improvements in processing efficiency to date comes from a study by Jaeggi et al. (2008). The study examined transfer of working memory training to one figural reasoning measure of fluid intelligence in a sample of 34 younger adults performing a complex working memory task. Participants in the intervention group completed $8,12,17$, or 19 daily training sessions. A no-contact control group was included as well. The trained working memory task was a dual n-back task, involving two strings of stimuli (letter and spatial locations) that were simultaneously presented. The value of the $n$ was adaptively adjusted based on each individual's performance. Results revealed statistically significant transfer effects for the groups training 17 or 19 days but not for the groups participating in 8 and 12 sessions. After the intervention groups were collapsed, the total net transfer gain was 0.4 standard deviation units. It may be difficult to imagine, based on face validity, that acquired knowledge during training (i.e., on the n-back task) would be relevant to performance on the figural reasoning measures. The same observation holds for several other recent studies on both younger adults (e.g., Dahlin et al., 2008; Karbach \& Kray, 2009; Persson \& Reuter-Lorenz, 2008) and older adults (Basak et al., 2008; Jennings et al., 2005; Karbach \& Kray, 2009), though effects tend to be reduced in older age (e.g., Dahlin et al., 2008). Thus, taking these studies at face value, one cannot but conclude that both younger and older adults possess residual capacity for improving the efficiency of several types of processes and that cognitive training programs can induce the necessary prolonged supply-demand mismatch. However, the fact that it is difficult to imagine that acquired knowledge improves performance on the transfer tasks applied in these studies does not necessarily mean that knowledge acquisition can be totally excluded as a cause of the transfer effect. Because of the exclusion logic, it will always be a matter of conceptual debate whether all knowledge factors have in fact been excluded.

To provide more convincing evidence for plasticity of processing efficiency in adulthood, researchers should administer multiple transfer tasks, as heterogeneous as possible (e.g., based on spatial, figural, and verbal content), in which the process that is the target of training is relevant for performance. If transfer effects are observed only on subsets of such tasks, the knowledge component will be difficult to exclude. On the other hand, if improvements are observed on most of the applied tasks of this kind, but not on tasks that do not assess the targeted process, alterations of processing efficiency can be concluded with greater certainty (for a demonstration, see Persson \& Reuter-Lorenz, 2008). Such an approach can also be effectively implemented by assessing transfer at the level of latent factors (cf. McArdle \& Prindle, 2008; Schmiedek, Lövdén, \& Lindenberger, 2009), in which the common variance of several transfer tasks that are heterogeneous on as many factors as possible, but homogenous over the process, is extracted. If transfer can be shown at the latent level, task-specific explanations become difficult to entertain and a more solid basis for claims that a certain intervention improves process efficiency is provided. Finally, the above approaches will be most effective if they are accompanied by detailed analyses of the cognitive components and strategies involved in both the trained and the transfer tasks. With such methodological care, and with results supported by empirically associated anatomical changes that exclude that improvements are based on flexibility, established functional effects can be used with greater confidence not only to confirm alteration in functional supply but also to establish which type (representation vs. process) of change in the range of performance and function is present. As things stand now, it is clear that both younger and older adults can expand their range of functioning by acquiring new knowledge but uncertain whether processing efficiency can be altered through plasticity in adulthood.

\section{Predictions and Future Research Questions}

Having discussed the framework's application for analyzing and understanding these two controversial issues in the behavioral neuroscience of aging (i.e., increased prefrontal cortex activation in aging and transfer of training gains), we next outline some more general and disparate predictions that our framework generates. In particular, we outline future research questions derived from our framework, predictions that enable better empirical testing of the framework's propositions, and recommendations that may serve to guide future cognitive intervention research.

First, an important cornerstone of our framework is that a mismatch between functional supply and environmental demands is a necessary condition for plastic change in adulthood. On the basis of this proposition, we suggest that cognitive interventions attempting to improve processing efficiency should administer multiple practice tasks that tap one central cognitive process. Applying one or a few tasks runs the risk of fostering development of strategies, which may result in circumventing the targeted process by capitalizing on knowledge acquisition and flexibility to close the mismatch (see also Schmidt \& Bjork, 1992). Targeting a narrowly defined specific cognitive process, rather than tasks that involve several processes, should maximize the duration and magnitude of a supply-demand mismatch (given limited amount of time and effort to spend) and thus the impetus for change of processing efficiency. Training of cognitive processes that play central roles in the cognitive architecture and brain areas that are active across a wide range of tasks (Persson \& Reuter-Lorenz, 2008) will maximize the applicability of the intervention effect (i.e., generality). Cognitive (executive) control processes and working memory are perhaps the most prominent abilities in this regard (D'Esposito \& Chen, 2006). Studies that distinguish themselves from the bulk of cognitive intervention studies on one or more of these features have also reported transfer effects (Basak et al., 2008; Dahlin et al., 2008; Jaeggi et al., 2008; Karbach \& Kray, 2009; Persson \& Reuter-Lorenz, 2008).

Second, we propose that manifestations of plasticity are codetermined by the degree of the supply-demand mismatch and by the level of intrinsic plastic capacity, which differs, for example, across brain systems and age. We note, in this vein, that several subcortical structures, such as the hippocampus, may retain their plasticity to a greater extent than neocortical areas in adulthood 
and old age. For example, neurogenesis might be limited in the adult human cortex (Bhardwaj et al., 2006). Future research is faced with the challenge of finding widely applicable processes that rely on structures that are plastic enough to be possible to alter.

Third, our framework asserts that (a) mismatches between functional supply and experienced environmental demands drive manifestations of plasticity; (b) mismatches need to be maintained for extended periods of time to induce plasticity; and (c) an individual's present level of flexibility determines the magnitude of the mismatch in interaction with environmental stimuli (e.g., task difficulty). Systems that can effortlessly respond to a change in demand with existing flexibility and systems that are not capable of fully experiencing environmental demands do not face a supply-demand mismatch. Therefore, cognitive training needs to engage the participant in a state of mental activity as far away as possible from the routine demand for which the participant's functional supply is optimized, by offering the maximum manageable difficulty at which the task can be performed, if high degrees of effort are exerted (Lindenberger \& Lövdén, 2006; Riediger, Li, \& Lindenberger, 2006), and thereby creating a maximum impetus for change. Moreover, it should be possible to construct this state of mismatch for individuals at all levels of performance, across all stages of learning, and for as long as needed to achieve the desired outcome. Cognitive tasks should be designed to allow for such effortful activity by continuously adapting task difficulty to the individual's current level of performance. Adapting difficulty may maximize and prolong the presence of a mismatch between functional supply and environmental demands and therefore prevent automatized (i.e., effortless) task execution by responses to alterations in supply with further increases of environmental demands. As a consequence of such a "plastic environment," we predict, adaptive difficulty will alter the function of performance increases on trained tasks over time and also increase transfer effects that reflect improvements in processing efficiency.

Several studies that included adaptive procedures and used placebo control groups by nonadaptive testing with low demands have reported larger transfer effects for those training under adaptive difficulty (e.g., Jaeggi et al., 2008; Jennings et al., 2005; Karbach \& Kray, 2009; Olesen et al., 2004). In themselves, these findings support the notion of a supply-demand mismatch as an important determinant of the magnitude of plastic alterations. We note that individualized difficulty adaptations and difficulty-performance relationships (e.g., time-accuracy functions) can be used in operationally defining our concept of a mismatch between functional supply and environmental demands. For example, administering a working memory task (e.g., n-back) at a presentation rate resulting in a specific level of accuracy (e.g., 50\%) identified for each participant separately can be viewed as equating the supply-demand mismatch across participants. In this way, the mismatch can be held constant across different groups of participants, and the necessary magnitude and duration (e.g., number of practice sessions) of the mismatch it takes to produce gains can be empirically examined. Alternatively, given the framework's prediction that too difficult or too easy tasks will be suboptimal for inducing manifestations of plasticity, the performance level can be manipulated and its empirical relation to manifestations of plasticity can be examined.

Fourth, we note that functional neuroimaging methods can, at least under some conditions and for some tasks, be used to measure the amount of mismatch for different individuals performing a task at a particular nominal difficulty level. For example, the bloodoxygen level dependent (BOLD) response is dependent on load manipulations in working memory tasks: Higher working-memory load (e.g., 3-back) is associated with higher frontoparietal activity (vs. rest) than lower working-memory load (e.g., 1-back; e.g., Braver et al., 1997; Callicott et al., 1999; Jansma, Ramsey, Coppola, \& Kahn, 2000). Consistent with our mismatch framework, however, too high working-memory load (e.g., 5-back) is often associated with lowered activity, such that BOLD activity forms the predicted inverted $U$-shape in relation to load (e.g., Callicott et al., 1999; Mattay et al., 2006; Nagel et al., 2009). Furthermore, the apex of the function (i.e., the point of maximum activation) differs across individuals in a performance-related manner (Nagel et al. 2009). Such measures may thus be used to measure each individual's supply-demand mismatch to a particular nominal task difficulty independently from the intrinsic capacity for plasticity and to examine the framework's assumption that interindividual differences in the degree of mismatch will predict manifestations of plasticity.

Fifth, our framework states that manifestations of plasticity can only be concluded if the range of performance and functioning has been altered (i.e., when both structural brain changes and functional consequences of these structural changes are present). For quite some time, macro-scale structural brain changes (i.e., changes beyond subcellular changes and structural changes associated with LTP and LTD) induced by a supply-demand mismatch were widely regarded as restricted to child development, but we now know that several of these mechanisms are present in adulthood and old age (for reviews, see Churchill et al., 2002; Li, 2003; Jessberger \& Gage, 2008; Kempermann, 2006). For example, MRI studies of younger adults have shown alterations in gray-matter density and volume as a function of learning abstract knowledge (Draganski, Gaser, et al., 2006; see also Maguire et al., 2000; Maguire, Woollett, \& Spiers, 2006) and of acquisition of complex motor skills (e.g., juggling; Draganski et al., 2004; see also Ilg et al., 2008). It would be premature to exclude that such changes may also be present in older adults. For example, Boyke, Driemeyer, Gaser, Büchel, and May (2008) conducted a juggling intervention with older adults, similar to the study conducted by Draganski et al. (2004). Results showed gray-matter increases in brain regions similar in kind to the training-related alterations found in younger adults, albeit smaller in magnitude. Though the exact biological nature of these morphological alterations remains unknown, several important manifestations of plastic alterations (e.g., synaptogenesis, angiogenesis) have been directly observed in both humans and adult animal models. For example, adult neurogenesis has been documented in humans (Eriksson et al., 1998), and environmental enrichment has been shown to increase neurogenesis, gliogenesis, and angiogenesis in both younger and older animals (Kempermann, Gast, \& Gage, 2002; for reviews, see Churchill et al., 2002; Jessberger \& Gage, 2008). These findings suggest that both younger and older adults possess residual plasticity, even by the strict criteria proposed here. Moreover, the human studies document how MRI and related techniques can be used to discriminate plasticity from flexibility.

Sixth, our framework proposes that stable levels of cognitive performance can be viewed as dynamic equilibrium states of reactions to changes in demand and supply. Moreover, such equi- 
librium states can be predicted to occur across different cognitive functions and brain structures. Thus, the mismatch model assumes that major investment of resources (e.g., time and effort) into a particular cognitive skill may induce disuse in other skills that may not be required anymore and reductions of functional supply to meet the reduced environmental demands on this skill. We predict that cognitive training, if it targets specific skills and strategies, may bring about reduced performance for nontargeted processes and negative alterations in brain structures not involved in trained task performance. This prediction is supported by cross-sectional evidence of larger posterior hippocampus and better identification of relations among landmarks, but smaller anterior hippocampus and worse visuospatial performance, in taxi drivers as compared to bus drivers (Maguire et al., 2000, 2006). Such a prediction also is consistent with evidence showing atrophied brain structure induced by loss of peripheral receptors (e.g., Draganski, Moser, \& Lummel, 2006).

Seventh, we submit that flexibility determines manifestations of plasticity through the supply-demand mismatch and thus in interaction with environmental stimuli. We argue that this proposition may help us to better understand the mixed pattern of findings regarding the association between cognitive performance and changes in cognitive performance from cognitive training interventions. Negative (e.g., Lövdén, Brehmer, Li, \& Lindenberger, 2009), positive (Kliegl, Smith, \& Baltes, 1990; Verhaeghen \& Marcoen, 1996), or no significant correlations (e.g., Jaeggi et al., 2008) between measures of levels of performance on tests of fluid intelligence and gains in performance from cognitive training have been reported. On the basis our framework, we argue that the specific nature of the intervention (i.e., the environmental stimuli) needs to be considered for understanding such associations. That is, interindividual differences in the impetus for change, as reflected in the match between environmental demands and functional supply, need to be considered in the equations that additionally include limitations of plasticity, genetic factors, individual differences in intrinsic plasticity capacity, and the individual's history of manifestations of plasticity. We predict that the mismatch parameter will play a particularly large role in determining the direction and degree of such associations when task demands are very low or high. In particular, we predict that, under low task demands, more flexible individuals, as indexed by better performance on the cognitive criterion test, may gain less in performance because there is no mismatch between supply and demand for these individuals. Under very high difficulty levels administered during training, however, lower performing individuals will experience less of a mismatch, because they cannot perform the task adequately and therefore will gain less than higher performing individuals from training. Under individually adjusted demands (e.g., through adaptive testing procedures), additional factors, such as genetically determined individual differences in the upper bounds of plasticity and functional upper limits of the task at hand, play a greater role and increase the need for formally modeling assumptions and outcomes.

\section{Concluding Remarks}

We commenced this research synthesis by asking whether the positive effects of enriched lifestyles on cognitive change in adulthood and old age (Bäckman et al., 1999; Fratiglioni et al., 2004;
Ghisletta et al., 2006; Kramer et al., 2004; Lövdén et al., 2005; for review, see Hertzog et al., 2009) reflect plastic alterations of cognitive performance induced by mental stimulation or a sparing of negative effects on cognition (e.g., depression, stress). That is, we asked the controversial question of whether plasticity shapes the terrain of cognitive aging depicted in Figure 1. The answer to this question depends on the definition of plasticity and may be more controversial than commonly acknowledged. Certainly, older adults are flexible and able to adapt their behavioral repertoire to environmental changes and declining cognitive functions. Both younger and older adults are also able to expand their range of functioning by acquiring new knowledge. Such plastic changes in knowledge can safely be assumed to shape individuals' paths through life, but they play less of a role for understanding the changes in cognitive processing efficiency (see Figure 1) that are at the heart of normal cognitive aging. Several recent studies have shown impressive demonstrations of structural brain changes in adulthood and old age, as well as changes in performance from cognitive training that transfer to untrained tasks. These findings provide some initial support for the notion that cognitive activity may indeed exert beneficial effects on the core processing components that underlie age-related cognitive decline. Due to the palpable difficulties in ascertaining transfer effects at the level of processing efficiency, however, the question of whether declines in processing efficiency can be attenuated through plasticity has not yet been answered. In the end, it may well turn out that the positive impact of an enriched lifestyle on the course of cognitive aging is mostly driven by the avoidance of negative pathways rather than by direct positive effects. However, the study of cognitive plasticity in old age is still in its infancy, and many studies of plasticity in adulthood lack theoretical grounding and methodological sophistication. We hope that the present framework helps future research shed more light on the nature and mechanisms of plasticity in adulthood and old age. We are convinced that understanding individuals' cognitive paths through life (see Figure 1) requires understanding of the interactions among primary causes, genetic factors, environmental factors, plasticity, and states of flexibility. We hope that the overarching term plasticity may ultimately give room to a set of interrelated probabilistic laws that overcome the divide between primary and secondary forms of adult development and aging.

\section{References}

Bäckman, L., Almkvist, O., Andersson, J., Nordberg, A., Winblad, B., Reineck, R., \& Långström, B. (1997). Brain activation in young and older adults during implicit and explicit retrieval. Journal of Cognitive Neuroscience, 9, 378-391.

Bäckman, L., \& Dixon, R. A. (1992). Psychological compensation: A theoretical framework. Psychological Bulletin, 112, 259-283.

Bäckman, L., Nyberg, L., Lindenberger, U., Li, S.-C., \& Farde, L. (2006). The correlative triad among aging, dopamine, and cognition: Current status and future prospects. Neuroscience \& Biobehavioral Reviews, 30, 791-807.

Bäckman, L., Small, B. J., Wahlin, Å., \& Larsson, M. (1999). Cognitive functioning in very old age. In F. I. M. Craik \& T. A. Salthouse (Eds.), Handbook of cognitive aging (Vol. 2, pp. 499-558). Mahwah, NJ: Erlbaum.

Baddeley, A. (2003). Working memory: Looking back and looking forward. Nature Reviews Neuroscience, 4, 829-839. 
Ball, K., Berch, D. B., Helmers, K. F., Jobe, J. B., Leveck, M. D., Marsiske, M., ... Advanced Cognitive Training for Independent and Vital Elderly Study Group. (2002). Effects of cognitive training interventions with older adults. JAMA, 288, 2271-2281.

Baltes, P. B. (1987). Theoretical propositions of life-span developmental psychology: On the dynamics between growth and decline. Developmental Psychology, 23, 611-626.

Baltes, P. B., Dittmann-Kohli, F., \& Kliegl, R. (1986). Reserve capacity of the elderly in aging-sensitive tests of fluid intelligence: Replication and extension. Psychology and Aging, 1, 172-177.

Baltes, P. B., \& Kliegl, R. (1992). Further testing of limits of cognitive plasticity: Negative age differences in a mnemonic skill are robust. Developmental Psychology, 28, 121-125.

Baltes, P. B., \& Lindenberger, U. (1988). On the range of cognitive plasticity in old age as a function of experience: 15 years of intervention research. Behavior Therapy, 19, 283-300.

Baltes, P. B., Lindenberger, U., \& Staudinger, U. (2006). Life span theory in developmental psychology. In W. Damon \& R. M. Lerner (Eds.), Handbook of child psychology: Vol. 1. Theoretical models of human development (6th ed., pp. 569-664). New York, NY: Wiley.

Baltes, P. B., \& Singer, T. (2001). Plasticity and the ageing mind: An exemplar of the biocultural orchestration of brain and behaviour. European Review, 9, 59-76.

Baltes, P. B., \& Willis, S. L. (1982). Plasticity and enhancement of intellectual functioning in old age: Penn State's adult development and enrichment project (ADEPT). In F. I. M. Craik \& E. E. Trehub (Eds.), Aging and cognitive processes (pp. 353-389). New York, NY: Plenum Press.

Banich, M. T. (1998). The missing link: The role of interhemispheric interaction in attentional processing. Brain and Cognition, 36, 128-157.

Barnett, S. M., \& Ceci, S. J. (2002). When and where do we apply what we learn? A taxonomy of far transfer. Psychological Bulletin, 128, 612637.

Basak, C., Boot, W., Voss, M., \& Kramer, A. F. (2008). Can training in a real-time strategy videogame attenuate cognitive decline in older adults? Psychology and Aging, 23, 765-777.

Beaulieu, C., \& Colonnier, M. (1989). Number and size of neurons and synapses in the motor cortex of cats raised in different environmental complexities. Journal of Comparative Neurology, 289, 178-181.

Bengtsson, S. L., Nagy, Z., Skare, S., Forsman, L., Forssberg, H., \& Ullén, F. (2005). Extensive piano practicing has regionally specific effects on white matter development. Nature Neuroscience, 8, 1148-1150.

Berlucchi, G., \& Buchtel, H. A. (2009). Neuronal plasticity: Historical roots and evolution of meaning. Experimental Brain Research, 192, 307-319.

Bhardwaj, R. D., Curtis, M. A., Spalding, K. L., Buchholz, B. A., Fink, D., Bjork-Eriksson, T., ... Frisén, J. (2006). Neocortical neurogenesis in humans is restricted to development. Proceedings of the National Academy of Sciences, USA, 103, 12564-12568.

Bherer, L., Kramer, A. F., Peterson, M. S., Colcombe, S., Erickson, K., \& Becic, E. (2005). Training effects on dual-task performance: Are there age-related differences in plasticity of attentional control? Psychology and Aging, 20, 695-709.

Boyke, J., Driemeyer, J., Gaser, C., Büchel, C., \& May, A. (2008). Training-induced brain structure changes in the elderly. Journal of Neuroscience, 28, 7031-7035.

Braver, T. S., Cohen, J. D., Nystrom, L. E., Jonides, J., Smith, E. E., \& Noll, D. C. (1997). A parametric study of prefrontal cortex involvement in human working memory. NeuroImage, 5, 49-62.

Brehmer, Y., Li, S.-C., Müller, V., von Oertzen, T., \& Lindenberger, U. (2007). Memory plasticity across the lifespan: Uncovering children's latent potential. Developmental Psychology, 43, 465-478.

Brion, J.-P., Demeurisse, G., \& Capon, A. (1989). Evidence of cortical reorganization in hemiparetic patients. Stroke, 20, 1079-1084.
Buckner, R. L., Corbetta, M., Schatz, J., Raichle, M. E., \& Petersen, S. E. (1996). Preserved speech abilities and compensation following prefrontal damage. Proceedings of the National Academy of Sciences, USA, 93, $1249-1253$.

Buonomano, D. V., \& Merzenich, M. M. (1998). Cortical plasticity: From synapses to maps. Annual Review of Neuroscience, 21, 149-186.

Buschkuehl, M., Jaeggi, S. M., Hutchison, S., Perrig-Chielo, P., Däpp, C., Müller, M., . . . Perrig, W. J. (2008). Impact of working memory training on memory performance in old-old adults. Psychology and Aging, 23, $743-753$.

Cabeza, R. (2002). Hemispheric asymmetry reduction in old age: The HAROLD model. Psychology and Aging, 17, 85-100.

Cabeza, R., Anderson, N. D., Locantore, J. K., \& McIntosh, A. R. (2002). Aging gracefully: Compensatory brain activity in high-performing older adults. NeuroImage, 17, 1394-1402.

Cabeza, R., Daselaar, S. M., Dolcos, F., Prince, S. E., Budde, M., \& Nyberg, L. (2004). Task-independent and task-specific age effects on brain activity during working memory, visual attention, and episodic retrieval. Cerebral Cortex, 14, 364-375.

Cabeza, R., Grady, C. L., Nyberg, L., McIntosh, A. R., Tulving, E., Kapur, S., . . Craik, F. I. M. (1997). Age-related differences in neural activity during memory encoding and retrieval: A positron emission tomography study. Journal of Neuroscience, 17, 391-400.

Callicott, J. H., Mattay, V. S., Bertolino, A., Finn, K., Coppola, R., Frank, J. A., .. Weinberger, D. R. (1999). Physiological characteristics of capacity constraints in working memory as revealed by functional MRI. Cerebral Cortex, 9, 20-26.

Chapman, M. (1988). Contextuality and directionality of cognitive development. Human Development, 31, 91-106.

Chen, R., Cohen, L. G., \& Hallett, M. (2002). Nervous system reorganization following injury. Neuroscience, 111, 761-773.

Churchill, J. D., Galvez, R., Colcombe, S., Swain, R. A., Kramer, A. F., \& Greenough, W. T. (2002). Exercise, experience and the aging brain. Neurobiology of Aging, 23, 941-955.

Conway, A. R. A., Kane, M. J., \& Engle, R. W. (2003). Working memory capacity and its relation to general intelligence. Trends in Cognitive Sciences, 7, 547-552.

Cooke, S. F., \& Bliss, T. V. P. (2006). Plasticity in the human central nervous system. Brain, 129, 1659-1673.

Craik, F. I. M., Winocur, G., Palmer, H., Binns, M. A., Edwards, M., Bridges, K., ... Stuss, D. T. (2007). Cognitive rehabilitation in the elderly: Effects on memory. Journal of the International Neuropsychological Society, 13, 132-142.

Dahlin, E., Stigsdotter Neely, A., Larsson, A., Bäckman, L., \& Nyberg, L. (2008, June 13). Transfer of learning after updating training mediated by the striatum. Science, 320, 1510-1512.

Davis, S. W., Dennis, N. A., Daselaar, S. M., Fleck, M. S., \& Cabeza, R. (2008). Que PASA? The posterior-anterior shift in aging. Cerebral Cortex, 18, 1201-1209.

DeFrias, C. M., Lövdén, M., Lindenberger, U., \& Nilsson, L.-G. (2007). Revisiting the dedifferentiation hypothesis with longitudinal multicohort data. Intelligence, 35, 381-392.

Derwinger, A., Stigsdotter Neely, A., Persson, M., Hill, R. D., \& Bäckman, L. (2003). Remembering numbers in old age: Mnemonic training versus self-generated strategy training. Aging, Neuropsychology, and Cognition, 10, 202-214.

D’Esposito, M., Aguirre, G. K., Zarahn, E., Ballard, D., Shin, R. K., \& Lease, J. (1998). Functional MRI studies of spatial and nonspatial working memory. Cognitive Brain Research, 7, 1-13.

D'Esposito, M., \& Chen, A. J. W. (2006). Neural mechanisms of prefrontal cortical function: Implications for cognitive rehabilitation. Progress in Brain Research, 157, 123-139.

Diamond, M. C., Lindner, B., Johnson, R., Bennett, E. L., \& Rosenzweig, M. R. (1975). Differences in occipital cortical synapses from environ- 
mentally enriched, impoverished, and standard colony rats. Journal of Neuroscience Research, 1, 109-119.

Dinse, H. R. (2006). Cortical reorganization in the aging brain. Progress in Brain Research, 157, 57-80.

Dinse, H. R., Godde, B., Hilger, T., Haupt, S. S., Spengler, F., \& Zepka, R. (1997). Short-term functional plasticity of cortical and thalamic sensory representations and its implication for information processing. In H.-J. Freund, B. A. Sabel, \& O. W. White (Eds.), Brain plasticity: Advances in neurology (pp. 159-178). Philadelphia, PA: Lippincott Raven.

Draganski, B., Gaser, C., Busch, V., Schuierer, G., Bogdahn, U., \& May, A. (2004). Neuroplasticity: Changes in grey matter induced by training. Nature, 427, 311-312.

Draganski, B., Gaser, C., Kempermann, G., Kuhn, H. G., Winkler, J., Büchel, C., \& May, A. (2006). Temporal and spatial dynamics of brain structure changes during extensive learning. Journal of Neuroscience, 26, 6314-6317.

Draganski, B., Moser, T., \& Lummel, N. (2006). Decrease of thalamic gray matter following limb amputation. NeuroImage, 31, 951-957.

Elbert, T., Pantev, C., Wienbruch, C., Rockstroh, B., \& Taub, E. (1995, October 13). Increased cortical representation of the fingers of the left hand in string players. Science, 270, 305-307.

Engert, F., \& Bonhoeffer, T. (1999). Dendritic spine change associated with hippocampal long-term synaptic plasticity. Nature, 399, 66-70.

Erickson, K. I., Colcombe, S. J., Wadhwa, R., Bherer, L., Peterson, M. S., Scalf, P. E., ... Kramer, A. F. (2007). Training-induced plasticity in older adults: Effects of training on hemispheric asymmetry. Neurobiology of Aging, 28, 272-283.

Eriksson, P. S., Perfilieva, E., Bjork-Eriksson, T., Alboom, A. M., Nordborg, C., Peterson, D., \& Gage, F. H.. (1998). Neurogenesis in the adult human hippocampus. Nature Medicine, 11, 1313-1317.

Farkas, E., \& Luiten, P. G. M. (2001). Cerebral microvascular pathology in aging and Alzheimer's disease. Progress in Neurobiology, 64, 575-611.

Fields, R. D. (2008). White matter in learning, cognition and psychiatric disorders. Trends in Neurosciences, 31, 361-370.

Fratiglioni, L., Paillard-Borg, S., \& Winblad, B. (2004). An active and socially integrated lifestyle in late life might protect against dementia. Lancet Neurology, 3, 343-353.

Garlick, D. (2002). Understanding the nature of the general factors in intelligence: The role of individual differences in neural plasticity as an explanatory mechanism. Psychological Review, 109, 116-136.

Gazzaniga, M. S., Ivry, R. B., \& Mangun, G. R. (2002). Cognitive neuroscience: The biology of the mind (2nd ed.). London, England: Norton.

Ghisletta, P., Bickel, J.-F., \& Lövden, M. (2006). Does activity engagement protect against cognitive decline in old age? Methodological and analytical considerations. Journals of Gerontology, Series B: Psychological Sciences and Social Sciences, 61, 253-261.

Ghisletta, P., \& Lindenberger, U. (2003). Age-based structural dynamics between perceptual speed and knowledge in the Berlin Aging Study: Direct evidence of ability dedifferentiation in old age. Psychology and Aging, 18, 696-713.

Grady, C. L., Maisog, J. M., Horwitz, B., Ungerleider, L. G., Mentis, M. J., Salerno, J. A., . . Haxby, J. V. (1994). Age-related changes in cortical blood flow activation during visual processing of faces and location. Journal of Neuroscience, 14, 1450-1462.

Grady, C. L., McIntosh, A. R., \& Craik, F. I. M. (2003). Age-related differences in the functional connectivity of the hippocampus during memory encoding. Hippocampus, 13, 572-586.

Greenough, W. T., Black, J. E., \& Wallace, C. S. (1987). Experience and brain development. Child Development, 58, 539-559.

Greenwood, P. M. (2007). Functional plasticity in cognitive aging: Review and hypothesis. Neuropsychology, 21, 657-673.

Grossman, M., Cooke, A., DeVita, C., Alsop, D., Detre, J., Chen, W., \& Gee, J. (2002). Age-related changes in working memory during sentence comprehension: An fMRI study. NeuroImage, 15, 302-317.
Hazy, T. E., Frank, M. J., \& O'Reilly, R. C. (2006). Banishing the homunculus: Making working memory work. Neuroscience, 139, 105118 .

Hebb, D. O. (1949). The organization of behaviour: A neuropsychological theory. New York, NY: Wiley.

Hertzog, C., Kramer, A. F., Wilson, R. S., \& Lindenberger, U. (2009). Enrichment effects on adult cognitive development: Can the functional capacity of older adults be preserved and enhanced? Psychological Science in the Public Interest, 9, 1-65.

Hihara, S., Notoya, T., Tanaka, M., Ichinose, S., Ojima, H., Obayashi, S., ... Iriki, A. (2006). Extension of corticocortical afferents into the anterior bank of the intraparietal sulcus by tool-use training in adult monkeys. Neuropsychologia, 44, 2636-2646.

Horn, J. L., \& Cattell, R. B. (1966). Age differences in primary mental ability factors. Journal of Gerontology, 21, 210-220.

Hultsch, D. F., Hertzog, C., Small, B. J., \& Dixon, R. A. (1999). Use it or lose it: Engaged lifestyle as a buffer of cognitive decline in aging? Psychology and Aging, 14, 245-263.

Ilg, R., Wohlschläger, A. M., Gaser, C., Liebau, Y., Dauner, R., Wöller, A., ... Mühlau, M. (2008). Gray matter increase induced by practice correlates with task-specific activation: A combined functional and morphometric magnetic resonance imaging study. Journal of Neuroscience, 28, 4210-4215.

Jacobs, K. M., \& Donoghue, J. P. (1991, February 22). Reshaping the cortical motor map by unmasking latent intracortical connections. Science, 251, 944-947.

Jaeggi, S. M., Buschkuehl, M., Jonides, J., \& Perrig, W. J. (2008). Improving fluid intelligence with training on working memory. Proceedings of the National Academy of Sciences, USA, 105, 6829-6833.

James, W. (1890). Principles of psychology. New York, NY: Holt.

Jansma, J. M., Ramsey, N. F., Coppola, R., \& Kahn, R. S. (2000). Specific versus nonspecific brain activity in a parametric N-back task. NeuroImage, 12, 688-697.

Jennings, J. M., Webster, L. M., Kleykamp, B. A., \& Dagenbach, D. (2005). Recollection training and transfer effects in older adults: Successful use of a repetition-lag procedure. Aging, Neuropsychology, and Cognition, 12, 278-298.

Jessberger, S., \& Gage, F. (2008). Stem cell-associated structural and functional plasticity in the aging hippocampus. Psychology and Aging, 23, 684-691.

Jones, S., Nyberg, L., Sandblom, J., Stigsdotter Neely, A., Ingvar, M., Petersson, K. M., \& Bäckman, L. (2006). Cognitive and neural plasticity in aging: General and task-specific limitations. Neuroscience \& Biobehavioral Reviews, 30, 864-871.

Karbach, J., \& Kray, J. (2009). How useful is executive control training? Age differences in near and far transfer of task-switching training. Developmental Science, 12, 978-990.

Kelly, A. M. C., \& Garavan, H. (2005). Human functional neuroimaging of brain changes associated with practice. Cerebral Cortex, 15, 10891102 .

Kempermann, G. (2006). Adult neurogenesis: Stem cells and neuronal development in the adult brain. Oxford, England: Oxford University Press.

Kempermann, G., Gast, D., \& Gage, F. H. (2002). Neuroplasticity in old age: Sustained fivefold induction of hippocampal neurogenesis by longterm environmental enrichment. Annals of Neurology, 52, 135-143.

Kinsbourne, M., \& Hicks, R. E. (1978). Functional cerebral space: A model for overflow, transfer and interference effects in human performance: A tutorial review. In J. Requin (Ed.), Attention and performance VII (pp. 345-362). Hillsdale, NJ: Erlbaum.

Kliegl, R., Smith, J., \& Baltes, P. B. (1989). Testing-the-limits and the study of adult age differences in cognitive plasticity of a mnemonic skill. Developmental Psychology, 25, 247-256.

Kliegl, R., Smith, J., \& Baltes, P. B. (1990). On the locus and process of 
magnification of age differences during mnemonic training. Developmental Psychology, 26, 894-904.

Klingberg, T., Fernell, E., Olesen, P. J., Johnson, M., Gustafsson, P., Dahlström, K., ... Westerberg, H. (2005). Computerized training of working memory in children with ADHD-a randomized, controlled trial. Journal of the American Academy of Child \& Adolescent Psychiatry, 44, 177-186.

Kolb, B. (1995). Brain plasticity and behavior. Mahwah, NJ: Erlbaum.

Konorski, J. (1948). Conditioned reflexes and neuron organization. Cambridge, England: Cambridge University Press.

Kopp, B., Kunkel, A., Mühlnickel, W., Villringer, K., Taub, E., \& Flor, H. (1999). Plasticity in the motor system related to therapy-induced improvement of movement after stroke. NeuroReport, 10, 807-810.

Kramer, A. F., Bherer, L., Colcombe, S. J., Dong, W., \& Greenough, W. T. (2004). Environmental influences on cognitive and brain plasticity during aging. Journals of Gerontology, Series A: Biological Sciences and Medical Sciences, 59, 940-957.

Kramer, A. F., Larish, J. F., \& Strayer, D. L. (1995). Training for attentional control in dual-task settings: A comparison of young and old adults. Journal of Experimental Psychology: Applied, 1, 50-76.

Kramer, A. F., \& Willis, S. L. (2002). Enhancing the cognitive vitality of older adults. Current Directions in Psychological Science, 11, 173-177.

Kyllonen, P. C., \& Christal, R. E. (1990). Reasoning ability is (little more than) working-memory capacity?!. Intelligence, 14, 389-433.

Lautrey, J. (2003). A pluralistic approach to cognitive differentiation and development. In R. J. Sternberg, J. Lautrey, \& T. I. Lubart (Eds.), Models of intelligence: International perspectives (pp. 117-131). Washington, DC: American Psychological Association

Li, S.-C. (2003). Biocultural orchestration of developmental plasticity across levels: The interplay of biology and culture in shaping the mind and behavior across the life span. Psychological Bulletin, 129, 171-194.

Li, S.-C., Brehmer, Y., Shing, Y.-L., Werkle-Bergner, M., \& Lindenberger, U. (2006). Neuromodulation of associative and organizational plasticity across the life span: Empirical evidence and neurocomputational modeling. Neuroscience \& Biobehavioral Reviews, 30, 775-790.

Li, S.-C., \& Lindenberger, U. (1999). Cross-level unification: A computational exploration of the link between deterioration of neurotransmitter systems and dedifferentiation of cognitive abilities in old age. In L.-G. Nilsson \& H. Markowitsch (Eds.), Cognitive neuroscience of memory (pp. 103-146). Toronto, Canada: Hogrefe \& Huber.

Li, S.-C., Schmiedek, F., Huxhold, O., Röcke, C., Smith, J., \& Lindenberger, U. (2008). Working memory plasticity in old age: Transfer and maintenance. Psychology and Aging, 23, 731-742.

Li, S.-C., \& Sikström, S. (2002). Integrative neurocomputational perspectives on cognitive aging, neuromodulation, and representation. Neuroscience \& Biobehavioral Reviews, 26, 795-808.

Liepert, J., Storch, P., Fritsch, A., \& Weiller, C. (2000). Motor cortex inhibition in acute stroke. Clinical Neurophysiology, 111, 671-676.

Lindenberger, U. (2001). Lifespan theories of cognitive development. In N. J. Smelser \& P. B. Baltes (Eds.), International encyclopedia of the social and behavioral sciences (Vol. 13, pp. 8848-8854). Amsterdam, the Netherlands: Elsevier.

Lindenberger, U., \& Baltes, P. B. (1997). Intellectual functioning in old and very old age: Cross-sectional results from the Berlin Aging Study. Psychology and Aging, 12, 410-432.

Lindenberger, U., \& Ghisletta, P. (2009). Cognitive and sensory declines in old age: Gauging the evidence for a common cause. Psychology and Aging, 24, 1-16.

Lindenberger, U., \& Lövdén, M. (2006). Co-constructing human engineering technologies in old age: Lifespan psychology as a conceptual foundation. In P. B. Baltes, P. A. Reuter-Lorenz, \& F. Rösler (Eds.), Lifespan development and the brain: The perspective of biocultural coconstructivism (pp. 350-375). Cambridge, England: Cambridge University Press.
Lindenberger, U., Li, S.-C., \& Bäckman, L. (2006). Delineating brainbehavior mappings across the lifespan: Substantive and methodological advances in developmental neuroscience [Editorial]. Neuroscience \& Biobehavioral Reviews, 30, 713-717.

Little, T. D., Lindenberger, U., \& Nesselroade, J. R. (1999). On selecting indicators for multivariate measurement and modeling with latent variables: When "good" indicators are bad and "bad" indicators are good. Psychological Methods, 4, 192-211.

Logan, G. D. (1988). Toward an instance theory of automatization. Psychological Review, 95, 492-527.

Lövdén, M., Brehmer, Y., Li, S.-C., \& Lindenberger, U. (2009). Plasticity of episodic memory performance in middle childhood to old age: Revisiting the magnification model. Manuscript in preparation.

Lövdén, M., Ghisletta, P., \& Lindenberger, U. (2005). Social participation attenuates decline in perceptual speed in old and very old age. Psychology and Aging, 20, 423-434.

Lövdén, M., \& Lindenberger, U. (2005). Development of intellectual abilities in old age: From age gradients to individuals. In O. Wilhelm \& R. Engle (Eds.), Understanding and measuring intelligence (pp. $203-$ 221). Thousand Oaks, CA: Sage.

Lustig, C., Shah, P., Seidler, R., \& Reuter-Lorenz, P. (2009). Aging, training, and the brain: A review and future directions. Neuropsychology Review, 19, 504-522.

Madden, D. J., Bennett, I. J., \& Song, A. W. (2009). Cerebral white matter integrity and cognitive aging: Contributions from diffusion tensor imaging. Neuropsychology Review, 19, 415-435.

Maguire, E. A., Gadian, D. G., Johnsrude, I. S., Good, C. D., Ashburner, J., Frackowiak, R. S. J., \& Frith, C. D. (2000). Navigation-related structural change in the hippocampi of taxi drivers. Proceedings of the National Academy of Sciences, USA, 97, 4398-4403.

Maguire, E. A., Woollett, K., \& Spiers, H. J. (2006). London taxi drivers and bus drivers: A structural MRI and neuropsychological analysis. Hippocampus, 16, 1091-1101.

Mahncke, H. W., Bronstone, A., \& Merzenich, M. M. (2006). Brain plasticity and functional losses in the aged: Scientific bases for a novel intervention. Progress in Brain Research, 157, 81-109.

Mahncke, H. W., Connor, B. B., Appelman, J., Ahsanuddin, O. N., Hardy, J. L., Wood, R. A., . . Merzenich, M. M. (2006). Memory enhancement in healthy older adults using a brain plasticity-based training program: A randomized, controlled study. Proceedings of the National Academy of Sciences, USA, 103, 12523-12528.

Malenka, R. C., \& Bear, M. F. (2004). LTP and LTD: An embarrassment of riches. Neuron, 44, 5-21.

Mattay, V. S., Callicott, J. H., Bertolino, A., Heaton, I., Frank, J. A., Coppola, R., ... Weinberger, D. R. (2000). Effects of dextroamphetamine on cognitive performance and cortical activation. NeuroImage, $12,268-275$.

Mattay, V. S., Fera, F., Tessitore, A., Hariri, A. R., Berman, K. F., Das, S., . . Weinberger, D. R. (2006). Neurophysiological correlates of agerelated changes in working memory capacity. Neuroscience Letters, 392, 32-37.

May, A., Hajak, G., Ganssbauer, S., Steffens, T., Langguth, B., Kleinjung, T., \& Eichhammer, P. (2007). Structural brain alterations following 5 days of intervention: Dynamic aspects of neuroplasticity. Cerebral Cortex, 17, 205-210.

Mayr, U. (2008). Introduction to a special section on cognitive plasticity in the aging mind. Psychology and Aging, 23, 681-683.

McArdle, J. J. (2001). A latent difference score approach to longitudinal dynamic structural equation analyses. In R. Cudeck, S. duToit, \& D. Sörbom (Eds.), Structural equation modeling: Present and future (pp. 342-380). Lincolnwood, IL: Scientific Software International.

McArdle, J. J., Ferrer-Caja, E., Hamagami, F., \& Woodcock, R. W. (2002). Comparative longitudinal structural analyses of the growth and decline 
of multiple intellectual abilities over the life span. Developmental Psychology, 38, 115-142.

McArdle, J. J., \& Prindle, J. J. (2008). A latent change score analysis of a randomized clinical trial in reasoning training. Psychology and Aging, 23, 702-719.

McNab, F., Varrone, A., Farde, L., Jucaite, A., Bystritsky, P., Forssberg, H., \& Klingberg, T. (2009, February 6). Changes in cortical dopamine D1 receptor binding associated with cognitive training. Science, 323, $800-802$

Mercado, E. (2008). Neural and cognitive plasticity: From maps to minds. Psychological Bulletin, 134, 109-137.

Møller, A. R. (2006). Neural plasticity and disorders of the nervous system. Cambridge, England: Cambridge University Press.

Moody, D. E. (2009). Can intelligence be increased by training on a task of working memory? Intelligence, 37, 327-328.

Munte, T. F., Altenmuller, E., \& Jancke, L. (2002). The musician's brain as a model of neuroplasticity. Nature Reviews Neuroscience, 3, 473478.

Nagel, I. E., Preuschhof, C., Li, S.-C., Nyberg, L., Bäckman, L., Lindenberger, U., \& Heekeren, H. R. (2009). Performance level modulates adult age differences in brain activation during a spatial working memory task. Proceedings of the National Academy of Sciences, USA, 106, 22552-22557.

Nesselroade, J. R. (1991). The warp and the woof of the developmental fabric. In R. M. Downs \& L. S. Liben (Eds.), Visions of aesthetics, the environment and development: The legacy of Joachim F. Wohlwill (pp. 213-240). Hillsdale, NJ: Erlbaum.

Noack, H., Lövdén, M., Schmiedek, F., \& Lindenberger, U. (2009). Cognitive plasticity in adulthood and old age: Gauging the generality of cognitive intervention effects. Restorative Neurology and Neurosciences, $27,535-553$.

Norman, D. A., \& Bobrow, D. G. (1975). On data-limited and resourcelimited processes. Cognitive Psychology, 7, 44-64.

Olesen, P. J., Westerberg, H., \& Klingberg, T. (2004). Increased prefrontal and parietal activity after training of working memory. Nature Neuroscience, 7, 75-79.

O'Sullivan, M., Jones, D. K., Summers, P. E., Morris, R. G., Williams, S. C. R., \& Markus, H. S. (2001). Evidence for cortical "disconnection" as a mechanism of age-related cognitive decline. Neurology, 57, 632-638.

Paillard, J. (1976). Réflexions sur l'usage du concept de plasticité en neurobiology [Reflections on the use of the concept of plasticity in neurobiology]. Journal de Psychologie Normale et Pathologique, 1, 33-47.

Park, D. C., \& Reuter-Lorenz, P. (2009). The adaptive brain: Aging and neurocognitive scaffolding. Annual Review of Psychology, 60, 173-196.

Pascual-Leone, A., Amedi, A., Fregni, F., \& Merabet, L. B. (2005). The plastic human brain cortex. Annual Review of Neuroscience, 28, 377401.

Persson, J., \& Nyberg, L. (2006). Altered brain activity in healthy seniors: What does it mean? Progress in Brain Research, 157, 45-56.

Persson, J., Nyberg, L., Lind, J., Larsson, A., Nilsson, L. G., Ingvar, M., \& Buckner, R. L. (2006). Structure-function correlates of cognitive decline in aging. Cerebral Cortex, 16, 907-915.

Persson, J., \& Reuter-Lorenz, P. A. (2008). Gaining control: Executive training and far transfer of the ability to resolve interference. Psychological Science, 19, 881-888.

Piaget, J. (1980). Introduction. In J. Piaget (Ed.), Les formes élémentaires de la dialectique (pp. 9-13). Paris, France: Éditions Gallimard.

Rajah, M. N., \& D'Esposito, M. (2005). Region-specific changes in prefrontal function with age: A review of PET and fMRI studies on working and episodic memory. Brain, 128, 1964-1983.

Ramón y Cajal, S. (1894). The Croonian lecture: La fine structure des centres nerveux. Proceedings of the Royal Society of London, 55, 444468.
Raz, N. (2007). Comment on Greenwood (2007): Which side of plasticity? Neuropsychology, 21, 676-677.

Raz, N., Lindenberger, U., Rodrigue, K. M., Kennedy, K. M., Head, D., Williamson, A., . . Acker, J. D. (2005). Regional brain changes in aging healthy adults: General trends, individual differences and modifiers. Cerebral Cortex, 1679-1689.

Reuchlin, M. (1978). Processus vicariants et différences individuelles [Vicarious processes and individual differences]. Journal de Psychologie, 2, 133-145.

Reuter-Lorenz, P. A., \& Cappell, K. A. (2008). Neurocognitive aging and the compensation hypothesis. Current Directions in Psychological Science, 17, 177-182.

Reuter-Lorenz, P. A., Jonides, J., Smith, E. E., Hartley, A., Miller, A., Marshuetz, C., \& Koeppe, R. (2000). Age differences in the frontal lateralization of verbal and spatial working memory revealed by PET. Journal of Cognitive Neuroscience, 12, 174-187.

Reuter-Lorenz, P. A., Stanczak, L., \& Miller, A. (1999). Neural recruitment and cognitive aging: Two hemispheres are better than one especially as you age. Psychological Science, 10, 494-500.

Riediger, M., Li, S.-C., \& Lindenberger, U. (2006). Selection, optimization, and compensation as developmental mechanisms of adaptive resource allocation: Review and preview. In J. E. Birren \& K. W. Schaie (Eds.), Handbook of the psychology of aging (6th ed., pp. 289-313). Amsterdam, the Netherlands: Elsevier.

Rönnlund, M., \& Nilsson, L.-G. (2006). Adult life-span patterns in WAIS-R block design performance: Cross-sectional versus longitudinal age gradients and relations to demographic factors. Intelligence, 34, 63-78.

Rönnlund, M., Nyberg, L., Bäckman, L., \& Nilsson, L.-G. (2005). Stability, growth, and decline in adult life span development of declarative memory: Cross-sectional and longitudinal data from a population-based study. Psychology and Aging, 20, 3-18.

Rosen, A. C., Prull, M. W., O'Hara, R., Race, E. A., Desmond, J. E., Glover, G. H., . . Gabrieli, J. D. E. (2002). Variable effects of aging on frontal lobe contributions to memory. NeuroReport, 13, 2425-2428.

Rossi, S., Miniussi, C., Pasqualetti, P., Babiloni, C., Rossini, P. M., \& Cappa, S. F. (2004). Age-related functional changes of prefrontal cortex in long-term memory: A repetitive transcranial magnetic stimulation study. Journal of Neuroscience, 24, 7939-7944.

Rypma, B., \& D'Esposito, M. (2001). Age-related changes in brainbehaviour relationships: Evidence from event-related functional MRI studies. European Journal of Cognitive Psychology, 13, 235-256.

Salthouse, T. A. (2006). Mental exercise and mental aging: Evaluating the validity of the use it or lose it hypothesis. Perspectives on Psychological Science, 1, 68-87.

Schaefer, S., Huxhold, O., \& Lindenberger, U. (2006). Healthy mind in healthy body? A review of sensorimotor-cognitive interdependencies in old age. European Review of Aging and Physical Activity, 3, 45-54.

Schaie, K. W. (1996). Intellectual development in adulthood: The Seattle longitudinal study. New York, NY: Cambridge University Press.

Schmidt, R. A., \& Bjork, R. A. (1992). New conceptualizations of practice: Common principles in three paradigms suggest new concepts for training. Psychological Science, 3, 207-217.

Schmiedek, F., Lövdén, M., \& Lindenberger, U. (2009). Hundred days of cognitive training enhance broad cognitive abilities in adulthood: Results from the COGITO study. Manuscript submitted for publication.

Sternberg, R. J. (2008). Increasing fluid intelligence is possible after all. Proceedings of the National Academy of Sciences, USA, 105, 67916792.

Stigsdotter Neely, A., \& Bäckman, L. (1995). Effects of multifactorial memory training in old age: Generalizability across tasks and individuals. Journals of Gerontology, Series B: Psychological Sciences and Social Sciences, 50, 134-140.

Stuss, D. T., Robertson, I. H., Craik, F. I. M., Levine, B., Alexander, M. P., 
Black, S., ... Winocur, G. (2007). Cognitive rehabilitation in the elderly: A randomized trial to evaluate a new protocol. Journal of the International Neuropsychological Society, 13, 120-131.

Sullivan, E. V., \& Pfefferbaum, A. (2006). Diffusion tensor imaging and aging. Neuroscience \& Biobehavioral Reviews, 30, 749-761.

Tanzi, E. (1893). I fatti e le induzioni dell'odierna istologia del sistema nervosa [The facts and inductions of modern histology of the nervous system]. Rivista Sperimentale di Freniatria e Medicina Legale delle Alienazioni Mentali, 19, 419-472.

Thorndike, E. L. (1906). Principles of teaching. New York, NY: Seiler.

Thorndike, E. L., \& Woodworth, R. S. (1901). The influence of improvement in one mental function upon the efficiency of other functions. Psychological Review, 8, 247-261.

Verhaeghen, P., \& Marcoen, A. (1996). On the mechanisms of plasticity in young and older adults after instruction in the method of loci: Evidence for an amplification model. Psychology and Aging, 11, 164-178.

Verhaeghen, P., Marcoen, A., \& Goossens, L. (1992). Improving memory performance in the aged through mnemonic training: A meta-analytic study. Psychology and Aging, 7, 242-251.

Ward, N. S., \& Cohen, L. G. (2004). Mechanisms underlying recovery of motor function after stroke. Neurological Review, 61, 1844-1848.
Will, B., Dalrymple-Alford, J., Wolff, M., \& Cassel, J. C. (2008). The concept of brain plasticity: Paillard's systemic analysis and emphasis on structure and function (followed by the translation of a seminal paper by Paillard on plasticity). Behavioural Brain Research, 192, 2-7.

Willis, S. L., Blieszner, R., \& Baltes, P. B. (1981). Intellectual training research in aging: Modification of performance on fluid ability of figural relations. Journal of Educational Psychology, 73, 41-50.

Wood, L. E., \& Pratt, J. D. (1987). Pegword mnemonic as an aid to memory in the elderly: A comparison of four age groups. Educational Gerontology, 13, 325-339.

Xerri, C. (2008). Imprinting of idiosyncratic experience in cortical sensory maps: Neural substrates of representational remodeling and correlative perceptual changes. Behavioural Brain Research, 192, 26-41.

Yesavage, J. A. (1984). Relaxation and memory training in 39 elderly patients. American Journal of Psychiatry, 141, 778-781.

Zelinski, E. (2009). Far transfer in cognitive training of older adults. Restorative Neurology and Neuroscience, 27, 455-471.

Received May 13, 2009 Revision received January 7, 2010 Accepted March 29, 2010

\section{ORDER FORM}

Start my 2010 subscription to Psychological Bulletin ISSN: 0033-2909

$\$ 102.00$ APA MEMBER/AFFILIATE

$\$ 261.00$ INDIVIDUAL NONMEMBER $\$ 699.00$ INSTITUTION

In DC and $M D$ add $6 \%$ sales tax

TOTAL AMOUNT DUE

Subscription orders must be prepaid. Subscriptions are on a calendar year basis only. Allow $4-6$ weeks for delivery of the first issue. Call for international subscription rates.

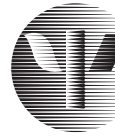

SEND THIS ORDER FORM TO

American Psychological Association

Subscriptions

750 First Street, NE

AMERICAN

PSYCHOLOGICAL

ASSOCIATION

Washington, DC 20002-4242

Call 800-374-2721 or 202-336-5600

Fax 202-336-5568 :TDD/TTY 202-336-6123

For subscription information,

e-mail: subscriptions@apa.org $\square$ Check enclosed (make payable to APA)

Charge my: $\square$ Visa $\square$ MasterCard $\square$ American Express

Cardholder Name

Card No. Exp. Date

Signature (Required for Charge)

\section{Billing Address}

Street

City State Zip

Daytime Phone

E-mail

\section{Mail To}

Name

Address

City State Zip

APA Member 